\title{
TURISMO Y TERRITORIO EN ÁREAS NATURALES PROTEGIDAS, PARQUE NACIONAL SANTA ROSA: DEL MONUMENTO NACIONAL A LA CONSERVACIÓN DEL BOSQUE TROPICAL SECO, ÁREA DE CONSERVACIÓN GUANACASTE, COSTA RICA
}

\author{
TOURISM AND TERRITORY IN NATURAL \\ PROTECTED AREAS - THE CASE OF SANTA ROSA \\ NATIONAL PARK: FROM NATIONAL MONUMENT \\ TO THE CONSERVATION OF THE TROPICAL FOREST, \\ GUANACASTE CONSERVATION AREA, COSTA RICA
}

Lilliam Quirós-Arias ${ }^{1}$

Universidad Nacional de Costa Rica, Costa Rica

\section{RESUMEN}

El turismo ligado a la conservación adquiere una importancia particular en Costa Rica a partir de los años ochenta; el interés por disfrutar y participar de la naturaleza marca un cambio en la práctica del turismo. El país alberga una gran riqueza de recursos naturales y culturales; así como paisajes rurales, caracterizados por áreas naturales protegidas, éstas rodeadas por agropaisajes y comunidades locales. En el presente estudio, se revisa la experiencia del Parque Nacional Santa Rosa, ubicado en el Área de Conservación Guanacaste (ACG), donde el desarrollo turístico es incipiente, con atractivos de tipo natural como núcleo de la actividad. La participación de las comunidades locales y su integración, forman parte de las preocupaciones recientes. La metodología incluyó revisión de

1 Directora-Académica Escuela de Ciencias Geográficas, Universidad Nacional de Costa Rica. Correo electrónico: lquiros@una.cr 
Lilliam Quirós-Arias. Tourism and territory in natural protected areas - the case of Santa Rosa National Park: from national monument to the conservation of the tropical forest, Guanacaste Conservation Area, Costa Rica

la información secundaria y, del mismo modo, se realizan entrevistas a los pobladores; además, se recolecta información de campo a través de repetidas visitas al área de interés. El ACG es una de las áreas protegidas que alberga importantes recursos para la investigación, siendo todavía un desafío aumentar la conservación de las áreas adyacentes incorporando la comunidad local2

Palabras clave: turismo, áreas naturales protegidas, conservación, ordenamiento territorial, Costa Rica.

\begin{abstract}
Since the 80 's, tourism related to conservation has been particularly important in Costa Rica. The interest in enjoying and being part of nature brought a change in tourism. The country hosts a great wealth of natural and cultural resources, as well as rural landscapes characterized by protected areas surrounded by natural landscapes and local communities. This document reviews the experience of the Santa Rosa National Park, located in the Guanacaste Conservation Area (ACG) -an area with an emerging tourist development and with natural attractions as its main resource. The participation of local communities and their integration are part of recent concerns. A revision of secondary information and interviews to townspeople are made. Moreover, field information is collected through different visits to the area of interest. The ACG is one of the protected areas that hosts important resources for research. However, increasing conservation in the neighboring areas including the local community is still a challenge.
\end{abstract}

Keywords: tourism, natural protected areas, conservation, land management, Costa Rica

\title{
1. Introducción
}

En Costa Rica, la preocupación por el tema ambiental y los valores asociados con éste, se manifiesta a través de las normas y decretos que se crean desde los primeros años de la República, incrementadas en el siglo siguiente, período en que el país atravesó un episodio de destrucción masiva de sus recursos naturales y la devastación de extensas áreas de bosque, y con ello la biodiversidad contenidas en estos espacios. Según FONAFIFO, de 1800 a 1950, la cobertura boscosa pasó de representar el 91,3\% del territorio a $64 \%$ y, de 1950 a 1987 , se redujo del $64 \%$ al $25 \%$. La protección de los espacios naturales protegidos en diferentes categorías, constituye su forma de resguardo; a partir de la creación de la primera área protegida, en el año 1963, el país experimenta un ascenso en la incorporación de áreas a su patrimonio natural. Según datos del SINAC (2011), las áreas silvestres protegidas suman 170 que representan el 26,28\% (1.340.872 hectáreas) de la superficie continental nacional y el $17,19 \%$ de la superficie marina nacional; 37 corredores oficializados representan el 34\% de la superficie

2 Este proyecto forma parte de una iniciativa PAPIIT, financiada por el Instituto de Geografía de la Universidad Autónoma de México entre 2013 y 2014, bajo el título de "Turismo y territorio en áreas naturales protegidas en México y América Central". 
continental, once sitios Ramsar; tres reservas de la biosfera y tres sitios de patrimonio mundial natural que, en su conjunto, poseen una gran importancia en la conservación de la biodiversidad, proveedores de una gama de servicios ecosistémicos y económicos sobre todo en el turismo, en la generación de energía hidroeléctrica y en el servicio básico de riego agrícola. Al respecto Furst, Moreno, García, y Zamora (2004), señalan que las áreas silvestres protegidas además de los servicios ecológicos, proporcionan otra serie de servicios de carácter económico, social e institucional, "su gestión inteligente genera diversas actividades de carácter socioeconómico en sus alrededores, que contribuyen al desarrollo socioeconómico del país, sobre todo al nivel local" (p.8).

Por su parte, durante la década de los años setenta el turismo inicia un período de ascenso en el país, fundamentado en el principal recurso que posee: sus áreas de conservación y los espacios naturales protegidos. El concepto de ecoturismo se promociona a nivel internacional con primeras experiencias exitosas, atrayendo turistas de todas partes del mundo, motivados por la práctica de un turismo de mayor respeto hacia la naturaleza. En años posteriores, los datos indican que seis de cada diez turistas que ingresan al país, visitan una o dos áreas naturales protegidas. El interés por desarrollar un turismo basado en la riqueza de sus recursos naturales y culturales, han convertido estas áreas en espacios altamente apreciados en el mercado nacional e internacional. Según la tipología de los núcleos turísticos primarios en América Central, realizada por Sánchez y Propin (2010), Costa Rica clasifica en 21 de los 25 núcleos turísticos primarios, núcleos cuyos recursos para el turismo son de orden natural.

De acuerdo con el ICT (2013), algunas características generales del turismo, indican que un 58,1\% de los extranjeros visitan alguna área protegida; para el $72,3 \%$ el motivo de la visita son vacaciones, ocio, recreo o placer; $50,1 \%$ independiente organizó su viaje desde su país y $69,6 \%$ unos amigos o familiares lo recomendaron; 11,4 estadía promedio (días) y $\$ 1.302,8$ (dólares de Estados Unidos) es el gasto medio por persona. Asimismo, la importancia económica del turismo es notable, según datos del Anuario Estadístico del Instituto Costarricense de Turismo (ICT), en el año 2013, ingresaron al país 2427.941, lo que representó 2 253,3 millones de US \$ por concepto de gastos; este dato coloca al turismo como el principal generador de divisas, por encima de productos agrícolas como el 
café, el banano y la piña; los dos primeros, tradicionalmente, han sido los mayores generadores de divisas. En la relación Turismo/PIB (\%), para el año 2013 éste representaba el 4,5 del total.

La relación entre el turismo y la conservación se hace evidente, la mayor oferta turística se localiza fuera del área metropolitana; según los datos del ICT, las principales actividades están relacionadas con sol y playa, observación de la flora y fauna, caminata por senderos, visita a los volcanes, actividades que se realizan durante la visitación de áreas naturales protegidas y áreas de conservación privadas.

\section{La conservación, el turismo y el territorio}

El surgimiento de las áreas naturales protegidas en América Latina, parte de la concepción del hombre como un ser destructor de la naturaleza, con una visión de las áreas naturales como intocables y susceptibles de ser alteradas. Se protegen estos espacios con riquezas ecológicas, con la intención de resguardar la vida salvaje, considerando que los espacios vacíos serían la única posibilidad de conservación (Diegues, 2000). Este enfoque, que se gesta en Estados Unidos y se concreta con la declaración del primer Parque Nacional Yellowstone (1872), se traslada a los países latinoamericanos, dándose un acelerado crecimiento en el número de áreas naturales protegidas, parques nacionales y reservas como estrategia para la conservación de la naturaleza, compitiendo con actividades agrícolas, privando en muchos casos a las comunidades del uso de sus recursos naturales a través de la expropiación y desalojo de poblaciones locales.

Es incuestionable que las áreas naturales protegidas, que empiezan a gestarse a finales del siglo XVIII y alcanzan su punto máximo en el siglo pasado, constituyen una fuente invaluable de beneficios ecosistémicos con un gran potencial en el aprovechamiento sostenible de los recursos naturales. En los espacios rurales, la contracción de actividades agrícolas abre espacios a otras actividades como el turismo, que bajo nuevas modalidades de aprovechamiento de recursos se constituyen en alternativas económicas para las comunidades locales; en el objetivo básico de la conservación se han incorporado otros en la perspectiva del uso público, interés científico o desarrollo socioeconómico.

Según Eagles, McCool, y Haynes (2002), "Una de las columnas vertebrales de las áreas protegidas desde el comienzo de su historia es la 
unión entre la población y el territorio, considerando a la población como una parte más del concepto, junto con la tierra y los recursos naturales y culturales" (p.8).

Aunque el objetivo principal de las áreas de conservación es la protección y conservación de los recursos naturales; la vinculación y la generación de alternativas que permitan una relación armoniosa sociedad-naturaleza, son todavía una deuda pendiente en muchas de los espacios y territorios. Estudios realizados muestran que en el caso de los países centroamericanos, "predominan convergencia áreas protegidas y comunidades con índices de desarrollo humano (IDH) bajo" (Informe III - Estado de la Región 2008). Muchas comunidades alrededor de los parques con tradición agrícola y ganadera se encuentran en condición de pobreza, falta de opción de empleo y escasa identificación con el área de conservación más cercana.

Según un estudio realizado por Centeno, González, y López. (2012), el área de Conservación Cordillera Volcánica Central, mostró que la comunidad con mayor identificación con el parque más cercano, es aquella en la que se han posicionado actividades culturales y ambientales organizadas conjuntamente con el parque y aquellas en las que la comunidad recibe beneficios económicos y de empleos, derivados del turismo. En comunidades en las cuales la relación se valoró como regular a mala, el turismo es visto por estas mismas comunidades como una opción de acercamiento entre la comunidad y el parque.

Como lo mencionan Nel y Andreu (2008): "las políticas de desarrollo turístico buscan la identificación de una estrategia para posicionar el país turísticamente y como instrumento para hacer rentables y autosostenibles las áreas protegidas, así como para promover el desarrollo local". Este último se vio beneficiado por el incremento en la creación de áreas de conservación que se registró a partir de 1969, y a su vez formaron parte de una estrategia para contribuir con la sostenibilidad de las áreas naturales protegidas.

De ahí que, como lo señala Pauchard (2000), queda claro que "los desafíos para el futuro de las áreas protegidas se centran en aumentar la conservación de las áreas adyacentes incorporando en mayor grado la comunidad local, mitigar los efectos negativos del ecoturismo, mantener el turismo de baja escala y promover la investigación" (p.51). Este mismo autor señala que "la incorporación de la comunidad al desarrollo de las áreas protegidas debe transformarse en una prioridad, y no sólo en una externalidad positiva 
del turismo. Esta puede ser la única vía de terminar con los problemas de ocupación ilegal y explotación de recursos dentro de las áreas protegidas, que subsisten en áreas deprimidas económicamente" (p.59).

La definición de las Políticas para las Áreas Silvestres Protegidas (ASP) del Sistema Nacional de Áreas de Conservación (SINAC) de Costa Rica (2011), recoge esta preocupación al menos en su planteamiento teórico y señala como temas prioritarios dirigidos a la articulación entre las áreas protegidas y las comunidades locales:

a. La gestión del sistema de ASP incorporará a las comunidades locales, pueblos indígenas, comunidades afrodescendientes y organizaciones de la sociedad civil, reconociendo el conocimiento tradicional y las prácticas ancestrales.

b. La gestión de las ASP tendrá un enfoque de equidad social, abordando y superando todas las formas sociales, económicas, culturales y políticas de exclusión e inequidad a través de mecanismos concretos de redistribución de riqueza, identificación de recursos y oportunidades, así como promoviendo la construcción de un balance intercultural y de género, en la toma de decisiones.

c. La gestión del turismo en las ASP deberá desarrollarse dentro de un marco de sostenibilidad, integrado con sus áreas de influencia y articulado con las políticas, planes y programas nacionales de conservación y turismo.

Se evidencia la necesidad de propiciar una mayor identificación de las comunidades con los parques, la conservación y el uso racional de los recursos, así como coadyuvar al mejoramiento de la calidad de vida de sus pobladores, propiciando alternativas sostenibles. En este sentido, según Maurín (2008) "la metodología sintética propia de la Geografía y su posición intermedia entre el conocimiento de la naturaleza y de la sociedad puede facilitar una mejor comprensión y tratamiento de algunos de los principales problemas que se plantean en la áreas protegidas, ya que casi siempre son problemas de coexistencia, compatibilidad o sinergia entre la conservación del medio y las actividades humanas" (p. 168).

\section{Costa Rica, conservación y turismo}


Costa Rica ha mostrado un rápido crecimiento de las áreas naturales protegidas; el principal aumento se produjo entre 1989 al 2009. En el gráfico siguiente se evidencia ese aumento.

Figura 1. Costa Rica: cantidad de Áreas Silvestres Protegidas por decenio, 1989-2009

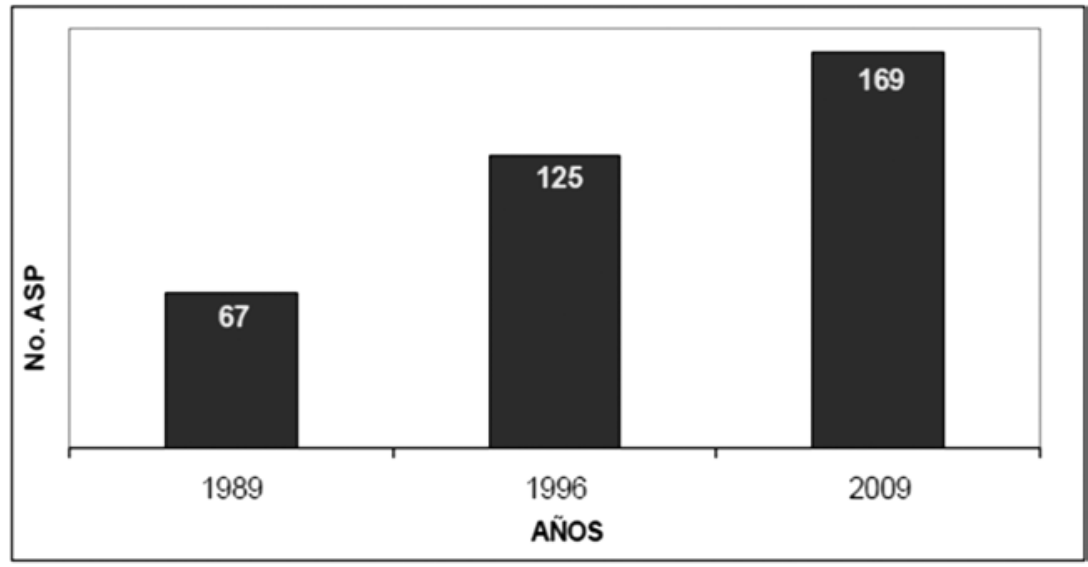

Fuente: SINAC, 2010.

La primera área protegida que se decretó en el país fue la Reserva Natural Absoluta Cabo Blanco, creada en 1963, seguida por el Parque Nacional Santa Rosa en 1971. Según datos del SINAC (2011), las áreas silvestres protegidas representan el 26,28\% del área total del país. En el siguiente cuadro se indican el número y extensión de las áreas silvestres protegidas, dividas en diez áreas de protección. En las categorías de parque nacional y reserva biológica, la presencia humana no está permitida. 
Lilliam Quirós-Arias. Tourism and territory in natural protected areas - the case of Santa Rosa National Park: from national monument to the conservation of the tropical forest, Guanacaste Conservation Area, Costa Rica

Cuadro 1. Costa Rica. Número y extensión de las áreas silvestres protegidas. 2013

\begin{tabular}{|l|c|c|}
\hline \multicolumn{1}{|c|}{ Categoría de manejo } & $\begin{array}{c}\text { Cantidad de áreas } \\
\text { silvestres protegidas }\end{array}$ & $\begin{array}{c}\text { Superficie total } \\
\text { Protegida en ha. }\end{array}$ \\
\hline Parques nacionales & 68 & 1.104 .839 \\
\hline Reservas biológicas & 8 & 26.840 \\
\hline Refugios nacionales de vida silvestre & 75 & 276.743 \\
\hline Zonas protectoras & 31 & 157.905 \\
\hline Reservas forestales & 9 & 216.378 \\
\hline Humedales & 13 & 68.547 \\
\hline Otras categorías * & 5 & 10.500 \\
\hline Totales & 169 & 1.861 .752 \\
\hline
\end{tabular}

Fuente: SINAC, 2013.

*Otras categorías: Monumento Nacional, Reserva Natural Absoluta, Estación Experimental.

Para efectos administrativos, el Sistema de Áreas de Conservación está divido en once áreas, las cuales son administradas por el Sistema Nacional de Áreas de Conservación (SINAC), redefinidas a partir de la publicación de la Ley de la Biodiversidad No 7788, publicado en La Gaceta 101 del 27/05/1998. El Parque Nacional Santa Rosa, forma parte del Área de Conservación Guanacaste (ACG), ubicada en el Pacífico Norte de Costa Rica e integra áreas tanto terrestres como marinas; representa además la mayor y única muestra de bosque seco que se encuentra desde México hasta Panamá, con un tamaño lo suficientemente grande para permitir su conservación a perpetuidad. Al respecto, Panadero Navarrete y Jover (2002), refiriéndose al potencial del Corredor Biológico Mesoamericano, ubican el ACG como una de las áreas donde queda preservada gran parte de la biodiversidad regional.

\subsection{La hacienda ganadera y la desaparición del bosque}

Desde la Colonia, la ganadería fue la actividad económica más importante en la provincia de Guanacaste; el comercio ganadero hacia Nicaragua y la ocupación de grandes extensiones de tierra para ser ocupadas por la actividad ganadera, dominaron el paisaje agrario. Muestra de ello es el gran tamaño de las extensiones, en hectáreas, de las haciendas; por ejemplo, Santa Rosa 6345, Murciélago 2700, El Jobo 4792, Paso Hondo 8600, Orosi 9720 
y Sapoa 1800. Esto llevó como consecuencia a que el bosque seco desapareciera aceleradamente desde el siglo XVII (Sequeira, 1985).

La hacienda ganadera favoreció la instalación de grandes extensiones de pastos, mientras que los fuegos anuales y la actividad ganadera perjudicaban la reinstalación del bosque y beneficiaban el dominio de una flora seca y resistente al fuego que provenía de la meseta de ignimbritas, de esta manera, se estableció y extendió la formación de sabana (Vargas, 1982-1983).

Por su parte, el área se integró tardíamente al territorio nacional, en 1858, el Tratado Cañas-Jerez, definió la línea fronteriza norte entre Costa Rica y Nicaragua. La frontera norte, La Cruz - Peñas Blancas, es área de tránsito de millones de dólares anuales en mercancías hacia Centroamérica. Actualmente, el área es una zona de cultivos de exportación, entre ellos la naranja.

Como se infiere de los datos del cuadro 2 , se ha dado el abandono de actividades agrícolas y ganaderas, las cuales emplean porcentajes de población inferiores para el último censo, mientras que en las actividades del sector terciario la ocupación de mano de obra se incrementa. Esta tendencia se observa en la recuperación de áreas de bosque como consecuencia del menor dinamismo de actividad ganadera, principalmente; mientras se mantienen pequeñas áreas dedicadas a la ganadería y agricultura de subsistencia.

Cuadro 2. Costa Rica, Cantón La Cruz de Guanacaste. Porcentaje de población ocupada por sector de actividad.

\begin{tabular}{|l|c|c|c|}
\hline \multirow{2}{*}{ Año } & \multicolumn{3}{|c|}{ Sector de actividad } \\
\cline { 2 - 4 } & Primario & Secundario & Terciario \\
\hline 2011 & 37.2 & 9.5 & 53.3 \\
\hline 2000 & 47.4 & 12.4 & 40.2 \\
\hline 1984 & 71.4 & 5.97 & 22.97 \\
\hline
\end{tabular}

Fuente: INEC, Censos de población, 1984, 2000 y 2011.

\subsection{Parque Nacional Santa Rosa su territorio y sus recursos}

En el Parque Nacional Santa Rosa (PNSR), fue primeramente declarado La Casona de Santa Rosa como Monumento Nacional por ley \#3694 el 1 de julio de 1966. El 27 de marzo de 1971, se declaró como Parque Nacional Santa Rosa, con diversas ampliaciones por decreto ejecutivo en 1977, 1982, 1987, 1990 y 1991. En 1980, se amplió con el sector Murciélago por Decreto Ejecutivo. 
El PNSR, forma parte del Sistema de Área de Conservación Guanacaste (ACG), comparte recursos con otras áreas de gran importancia como el Parque Nacional Rincón de la Vieja, Reserva de Vida Silvestre Junquillal y Parque Guanacaste, entre otros. En el mapa 2, se muestra la distribución del Área de Conservación Guanacaste, donde resalta la gran extensión marina que está bajo protección, vertebradas las mismas por la Carretera Interamericana. El área limita al norte con Nicaragua con Corredor Fronterizo.

ElACG, en su conjunto, fue establecido en 1986, con el propósito de conservar un ecosistema completo de bosque tropical seco y sus ecosistemas adyacentes de bosque nuboso, bosque lluvioso y zona marino costera. Inicia este proceso con 10.400 hectáreas y, en años posteriores, se enfoca a la compra de tierras privadas. Está constituida por 120.000 ha en la zona terrestre y 43.000 en la zona marina. Se estima que existen aproximadamente 235,000 especies (65\% del estimado de las especies en Costa Rica) y un $2.6 \%$ de la biodiversidad mundial (SINAC, 2013). En el año 1999, fue declarada Patrimonio de la Humanidad por la Unesco. (Véase mapa 1).

Esta área conserva el bosque seco más representativo en Centroamérica, incluye especies forestales como: guanacaste, pochote, guapinol, indio desnudo y caoba. Especies mamíferos como: venado cola blanca, mono congo, mono cara blanca, pizotes, así como numerosas especies de aves y anfibios. El Instituto Internacional en Conservación y Manejo de Vida Silvestre (ICOMVIS) de la Universidad Nacional, estudia la importancia del ACG para la conservación del jaguar (Panthera onca) y sus presas, como especies indicadoras de la recuperación del bosque (Amit, Alfaro y Carrillo, 2007). 
Lilliam Quirós-Arias. Turismo y territorio en áreas naturales protegidas, Parque Nacional Santa Rosa: del monumento nacional a la conservación del bosque tropical seco, Área de Conservación Guanacaste, Costa Rica
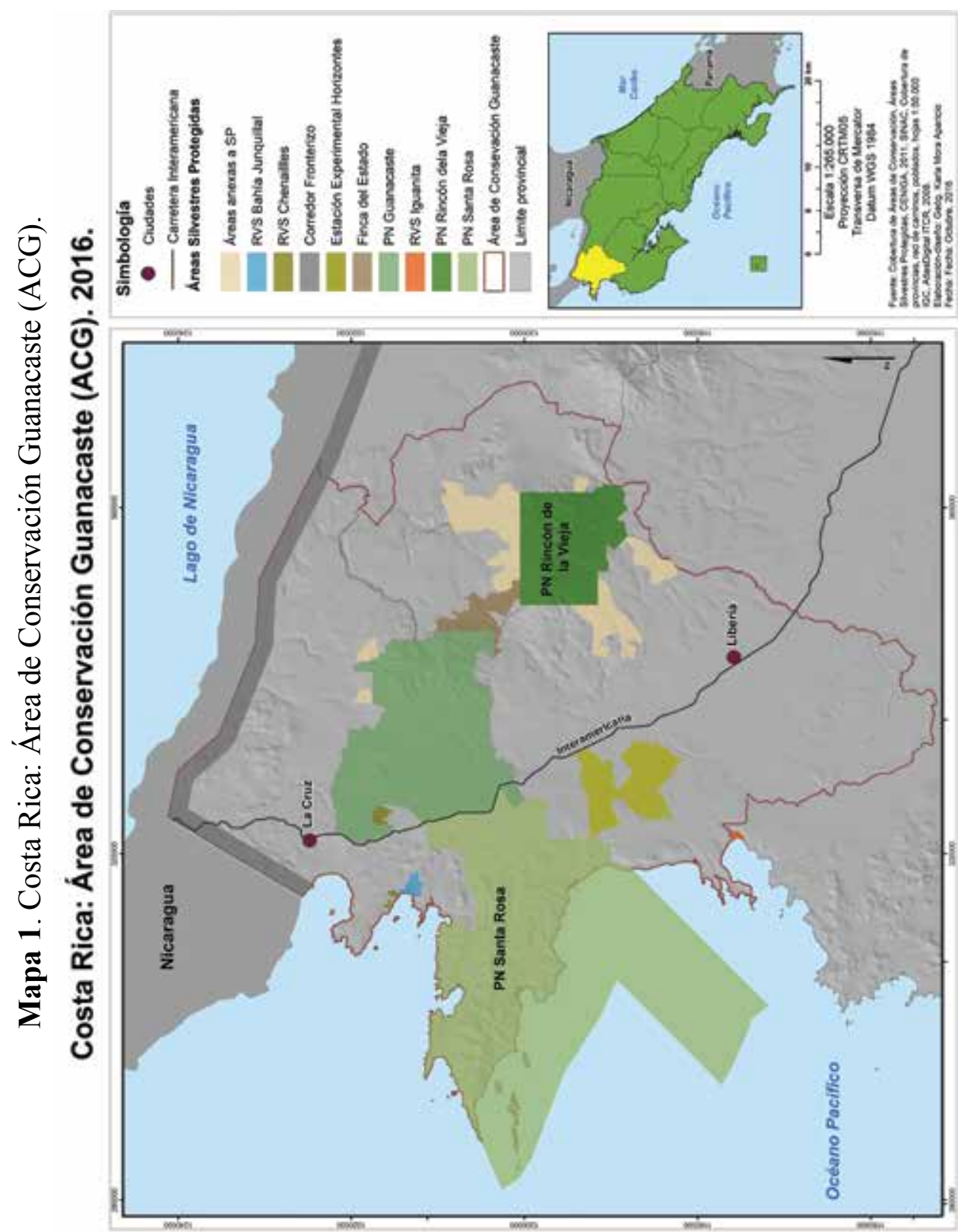
Por su parte, el PNSR integra 43 mil hectáreas marinas y 38 mil hectáreas terrestres; su instauración ha permitido restaurar antiguas áreas de pastizales en bosques secundarios en procesos de sucesión natural y bosque primario; se define como bosque seco tropical, caracterizado por soportar una larga estación seca (seis o siete meses al año), con vegetación que pierde las hojas durante la época seca, con fuentes de agua muy escasas. Con la creación del Parque Nacional Santa Rosa, en 1971, se inició el proceso de sucesión vegetal; los fuegos anuales que recorren la sabanas de la zona tropical son, por lo general, de origen antrópico (Vargas, 2011). Este mismo autor señala que si la sabana se protege, evoluciona hacia formas arbustivas de matorral o formaciones forestales de bosque seco.

El problema de fragmentación territorial está presente en el ACG, el trazado de la red de transporte aísla entre sí los relictos naturales, y expone a la mortalidad a especies faunísticas del área. Está propuesto un proyecto de ampliación de esta vía nacional; se realizan gestiones para que en los $13 \mathrm{~km}$ que comprende el ACG no se amplíe la misma, ya que esto traería una alta destrucción de la flora y expondría aún más a los animales que diariamente cruzan la vía.

\subsection{Rasgos geográficos principales que definen el Parque Na- cional Santa Rosa}

El Parque Nacional Santa Rosa se ubica en el cantón de La Cruz, Guanacaste, cantón con una extensión de $1.383 \mathrm{~km}^{2}$, el $50 \%$ de la superficie se encuentra bajo protección por parte del SINAC, una de las de mayor importancia el PNSR.

De acuerdo al mapa geológico de Costa Rica (1968), la geología del área se caracteriza por poseer las rocas más antiguas de Costa Rica. El PNSR está compuesto por rocas intrusivas denominada peridotita de la Península de Santa Elena (TT), y algunos fragmentos del Complejo de Nicoya (Kvs): grauwacas, ftanitas, lutitas ftaníticas, calizas silíceas, coladas de basalto, aglomerados de basalto e instrusiones de diabasos, gabros y dioritas. Hacia el norte del PNSR, se encuentran materiales de la Formación Barra Honda (Tep-bh).

Geomorfológicamente el área se caracteriza por Formas de Denudación originadas en rocas ígneas. Se ubican las serranías y valles profundos de la Península de Santa Elena. Se localizan además Formas de 
Sedimentación Aluvial: conos coluvio-aluviales y conos coluvio-aluviales con posible influencia marina. Al norte del PNSR se localizan Formas de Origen Estructural; Monoclinal de Murciélago, Anticlinal de Descartes y el Sinclinal de Cuajiniquil.

Gran parte del territorio en el cual se ubica el PNSR y alrededores, de acuerdo a las zonas de vida, en el piso basal se localiza el bosque tropical seco (bs-t), siendo la muestra representativa más grande de Centroamérica y en el piso premontano se localiza el bosque húmedo premontano transición a basal.

El régimen de precipitaciones se caracteriza por largos períodos de sequía, que va de noviembre a mayo-junio. En los últimos años las sequias prolongadas caracterizan el paisaje de este territorio, siendo una de las áreas más afectadas por el fenómeno del niño y las proyecciones del cambio climático. La red hidrológica se caracteriza por la presencia de ríos intermites y en general la insuficiencia de agua en el PNSR limita el desarrollo turístico de áreas costeras. Las comunidades se ven limitadas por el acceso a agua potable, siendo que en época seca esta se convierte en una de las principales limitantes para el bienestar de la población.

\subsection{Legado histórico-cultural del Parque Nacional Santa Rosa}

El PNSR está caracterizado por la existencia de importantes recursos naturales y culturales destinados a la actividad turística. Dentro de los más importantes están la Hacienda Santa Rosa y el Sector Murciélago; ambos guardan un legado histórico de gran relevancia para el país.

a. La Hacienda Santa Rosa. Fue uno de los lugares más importantes para el comercio entre Liberia y Rivas de Nicaragua, símbolo de la cultura sabanera guanacasteca. El 20 de marzo de 1856 se dio la histórica lucha contra las intenciones esclavistas de los filibusteros. Esta hacienda evoca la hazaña de un pequeño grupo de soldados costarricenses que se enfrentan, por primera vez, a las fuerzas de William Walker. Alrededor de este recurso, se articulan otros de gran belleza escénica y paisajística como: Sendero Indio Desnudo, Mirador Tierras Emergidas, Mirador Monumento a los Héroes, Museo Histórico Casona de Santa Rosa, Sendero Los Patos, Mirador Valle Naranjo, Playa Naranjo (práctica el surfing) y la roca Peña Bruja. 
Las playas Nancite y Naranjo ubicados en PNSR son de gran belleza escénica e importantes áreas para el desove de tortugas marinas como la lora y la baula.

La estructura original del Museo Histórico Casona de Santa Rosa fue construida en 1750; actualmente, en este museo se exhiben fotografías, cuadros, pinturas y equipo militar que conmemora la batalla de la Hacienda Santa Rosa. Se ubican cerca de la Casona los corrales de piedra, construidos en el año de 1700 (aproximadamente), en ellos se observa aún el bramadero, y el baño de inmersión.

La Casona, recurso turístico principal del parque fue incendiada en 2001 y reconstruía posteriormente; recientemente, requirió nuevas reparaciones para mantenerla en condiciones adecuadas y conservar su historia. Asimismo, el PNSR alberga importantes recursos para la investigación: laboratorios, programas de Ecoturismo, programa de Educación Biológica, estancias para investigadores, sala de conferencia y otra infraestructura y equipamiento. (Véase figura 2). 
Figura 2. Parque Nacional Santa Rosa, Casona Santa Rosa, Recurso turístico principal.

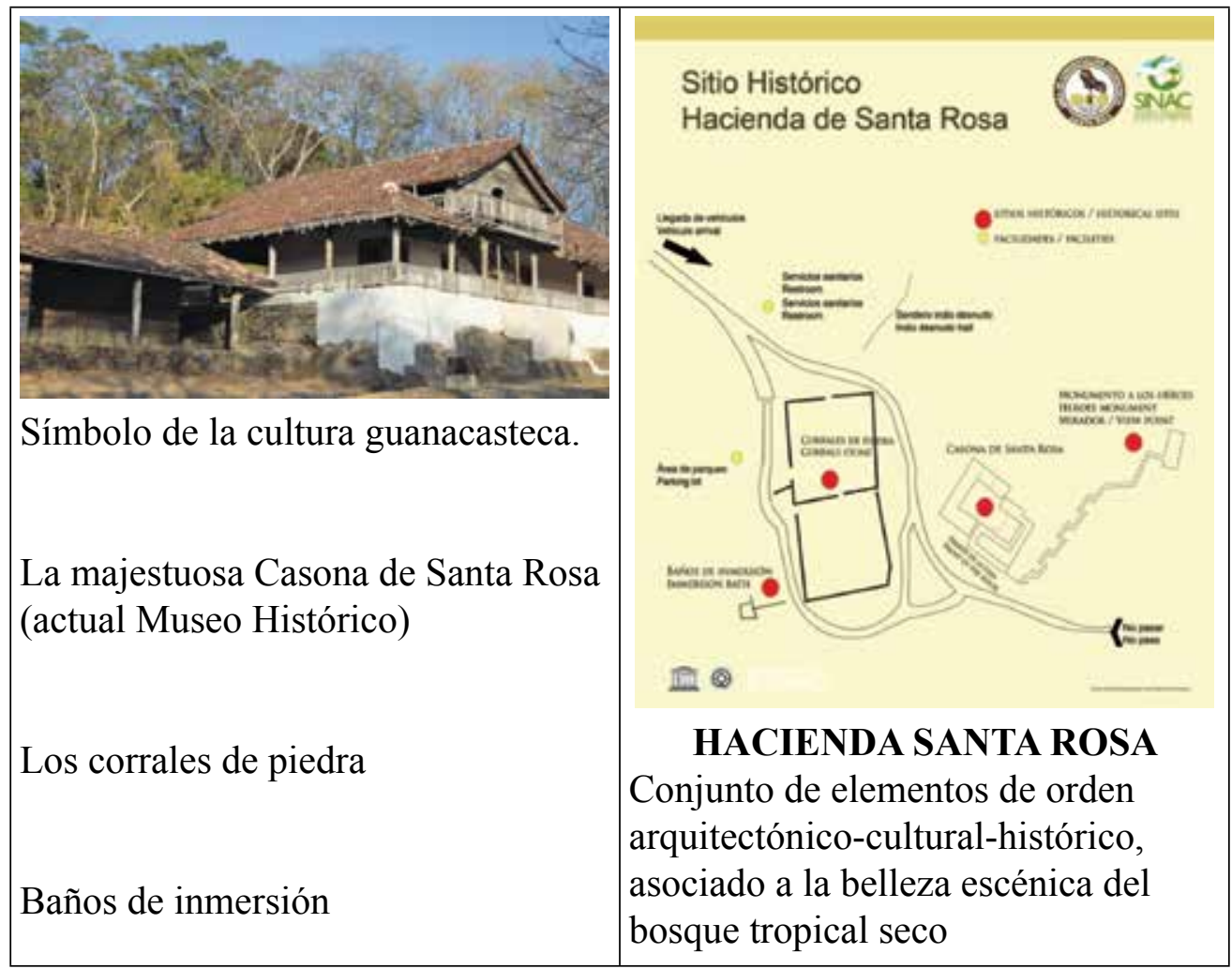

Fuente: Sistemas de Información Geográfica, ACG. 2004.

b. Sector Murciélago. La Finca Murciélago registra su existencia desde el año 1663, pasando por varios propietarios; en 1966, pasa a ser propiedad de Luis Somoza Debayle, expresidente de Nicaragua. Durante la Revolución Sandinista, en el año 1979, el gobierno de Costa Rica expropia la finca a la familia Somoza y, en 1980, parte de la misma, pasa a formar parte del Área de Conservación Guanacaste. Actualmente, la casona de la Hacienda Murciélago alberga la Escuela Nacional de Policías de Costa Rica, a la cual se le asignaron 70 hectáreas; gran parte del área está destinada a la protección, conservación y como sitio de entrenamiento policial. En el sector Murciélago entre las áreas destinadas al turismo están: Sendero el 
Lilliam Quirós-Arias. Tourism and territory in natural protected areas - the case of Santa Rosa National Park: from national monument to the conservation of the tropical forest, Guanacaste

Conservation Area, Costa Rica

Nance, Poza el General, Playa el Hachal, Playa Bahía Santa Elena y Playa Blanca; estas playas son poco visitadas por su difícil acceso pero de gran belleza paisajística. (Véase figura 3).

Figura 3. Hacienda Murciélago de gran valor histórico

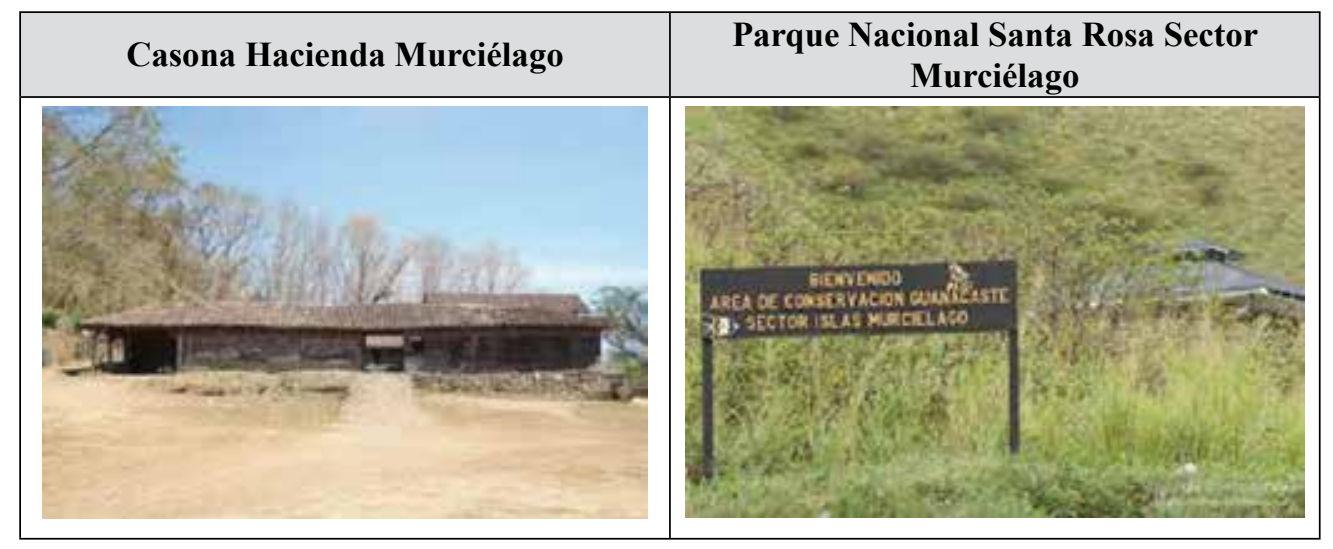

Maurín (2008), propone una clasificación jerárquica de los recursos, de acuerdo con a recurso motivo principal, recursos motivos significativos y otros recursos motivos de menor interés. Con base en esta clasificación, se propone la siguiente clasificación para los recursos del PNSR. (Véase cuadro 3).

Cuadro 3. Costa Rica. Área de Conservación Guanacaste. Parque Nacional Santa Rosa. Clasificación jerarquizada de los recursos, 2014

\begin{tabular}{|c|c|c|}
\hline $\begin{array}{c}\text { Recurso o motivo } \\
\text { principal }\end{array}$ & $\begin{array}{l}\text { Recursos o motivos } \\
\text { significativo }\end{array}$ & $\begin{array}{c}\begin{array}{c}\text { Otros recursos de motivos de } \\
\text { interés }\end{array} \\
\end{array}$ \\
\hline \multicolumn{3}{|c|}{ Sector Santa Rosa } \\
\hline Casona Santa Rosa & $\begin{array}{l}\text { Monumento a Héroes } \\
\text { Playa Nancite } \\
\text { Playa Naranjo } \\
\text { Desove de tortugas } \\
\text { Apreciación de flora y fauna }\end{array}$ & $\begin{array}{l}\text { Sendero Natural Indio Desnudo } \\
\text { Vista del Mirador Tierras } \\
\text { Emergidas, Santa Rosa } \\
\text { Roca Peña Bruja } \\
\text { Sendero Los Patos } \\
\text { Mirador Playa Naranjo } \\
\text { Sendero Carbonal } \\
\text { Sendero al Pozo } \\
\text { Mirador Valle Naranjo } \\
\text { Cerros Carbonal } \\
\text { Cerros Santa Elena }\end{array}$ \\
\hline
\end{tabular}




\begin{tabular}{|l|l|l|}
\hline $\begin{array}{c}\text { Recurso o motivo } \\
\text { principal }\end{array}$ & \multicolumn{1}{|c|}{$\begin{array}{c}\text { Recursos o motivos } \\
\text { significativo }\end{array}$} & $\begin{array}{c}\text { Otros recursos de motivos de } \\
\text { interés }\end{array}$ \\
\hline \multicolumn{3}{|c|}{ Sector Murciélago } \\
\hline Bahía Santa Elena & Playa Bahía Santa Elena & Sendero el Nance \\
\hline & Playa el Hachal & Poza el General \\
\hline & Playa Blanca & \\
\hline
\end{tabular}

Fuente: Elaboración propia, utilizando propuesta metodológica de Maurín (2008, p.170)

\subsection{Recursos marino-costero adyacentes al Parque Nacional Santa Rosa}

La zona marino costera, se extiende desde la Bahía Thomas, en La Cruz, hasta los cerros Carbonal en Liberia; abarcan $110 \mathrm{~km}$. Incluye la protección del archipiélago más importante del país, con quince islas; entre ellas: Isla Murciélago; Los Negritos; Bolaños; Los Cabos, en Bahía Salinas; islas Muñecos y Loros, en bahía Junquillal; de gran importancia por la anidación de aves marinas. La Estación Biológica Nancite es escenario de estudios de la tortuga lora y en la Estación de Isla San José se realizan estudios sobre corales.

En la zona costera se ubican las comunidades Cuajiniquil, El Jobo y Soley, comunidades que se han enfrentado con el parque por la realización de actividades ilegales de pesca artesanal, pesca de camarón y buceo. Según (ACG, 2014), existen registros sobre comunidades coralinas y de arrecifes, especies de peces como velas, marlines, tiburones, jureles, atunes, manta rayas, las rayas doradas y la gavilana, y especies de mamíferos marinos como delfines y ballenas, especialmente jorobadas. Además, en el área arriban tortugas marinas como la tortuga lora, la verde del Pacífico, la baula y carey.

Esta área marina es testigo del Afloramiento de Papagayo que, según ACG (2014), "se produce durante la estación seca, cuando los vientos alisios del norte empujan las masas de aguas superficiales del Océano Pacífico, lo cual obliga a subir a las aguas profundas más frías, traen consigo nutrientes del fondo hacia la superficie del mar, incrementando la productividad primaria". Según Méndez (2005), esto se asocia "a zonas del área marina del ACG que los pescadores las han denominado santuarios. Esta zona recibe una fuerte presión por la pesca y el desarrollo del turismo, que se ha venido asentando en los últimos años" (p.55). 
El ACG, en su conjunto, trabaja en la Estrategia para el Ordenamiento de las Acciones de Conservación y Manejo en las 43.000 hectáreas del Sector Marino Protegido del Área de Conservación Guanacaste, la cual pretende asegurar que la biodiversidad marina y costera del Sector Marino Protegido y sus ecosistemas asociados, sean conservados y manejados eficientemente para asegurar su existencia; donde la sensibilidad ambiental de sus vecinos y usuarios contribuye a su conservación y desarrollo. En el sector marino protegido está permitida la visitación con fines recreativos (el buceo recreativo u observación), la realización del surfing y el camping, en la Isla San José, actividades orientadas por las regulaciones correspondientes.

Según datos de ACG (2014), en la conformación de lo que es el ACG, se han invertido fondos provenientes de "nueve países, de más de 50 fundaciones internacionales y de más de 10.000 donantes particulares para un monto mayor a los $\$ 50$ millones de dólares. Más de 300 propiedades fueron adquiridas para conformar esta unidad biológica que hoy día está en proceso de restauración y conservación y que representa el $2 \%$ de Costa Rica y es depositaria del $2.6 \%$ de la biodiversidad mundial". http://www. acguanacaste.ac.cr/acg/que-es-el-acg.

\section{Las comunidades cercanas al Parque Nacional Santa Rosa y no- dos de interconexión}

En los alrededores del Parque Nacional Santa Rosa, se establece un paisaje caracterizado por su rica historia asociada con las haciendas ganaderas.

\subsection{De jornaleros a parceleros agrícolas y pescadores: comuni- dad de Cuajiniquil}

La comunidad de Cuajiniquil se cimentó en la realización de actividades primarias: agricultura y pesca; una gran mayoría de sus pobladores laboraba como trabajadores agrícolas de la Hacienda Murciélago. A raíz de la expropiación de la hacienda, de aproximadamente 15.757,95 hectáreas, una parte (cerca de 2.000 ha) se cedió al ITCO, INDER hoy día; una importante porción al Parque Nacional Santa Rosa y otra porción (70 ha) a la Policía Nacional. Algunos pobladores de la comunidad de Cuajiniquil, antiguos trabajadores, una vez expropiada la hacienda, se unen para gestionar acceso a las tierras. Alrededor de 89 familias (470 personas) fueron beneficiadas con aproximadamente 20 y 15 hectáreas a cada una. De los 
solicitantes, según datos del ITCO (1979), 22 eran de origen nicaragüense, que habían legalizado su condición de residencia en Costa Rica.

Según la valoración que el ITCO realizó en 1979, la finca es bastante quebrada, con pequeñas áreas para agricultura por sus condiciones topográficas, en gran parte costea el mar a la altura de Bahía Cuajiniquil y Playa Blanca; esta condición favorece la utilización de una gran parte de la finca para la conservación, tierras que fueron cedidas al ACG.

Desde sus inicios, el suministro de agua ha sido un tema problemático en la comunidad, ya que no había (1979) un suministro de agua planificada. Según ITCO (1979), en ese momento la mayoría de la población se abastecía de pozos, quebradas y nacientes. Posteriormente, éste ha sido uno de los temas que han enfrentado al PNSR con la comunidad, algunas parcelas colindantes no tienen agua; tradicionalmente la han tomado del Parque, la cual la utilizan para riego y uso doméstico. Aunque hay documentos que formalizan la concesión, en los últimos años, este suministro no ha estado garantizado.

\subsection{De la Hacienda el Jobo a la comunidad Colonia Bolaños}

La comunidad de Colonia Bolaños, asentada sobre la Carretera Interamericana Norte, fue fundada bajo la modalidad de una invasión de la Hacienda el Jobo, que estaba destinada a la ganadería extensiva; muchas de estas tierras no tienen vocación agrícola. La finca original sobre la cual se estableció el asentamiento Colonia Bolaños tenía 1417 hectáreas, de las cuales 949 ha se repartieron en 33 entre familias por parte del ITCO (25 hectáreas a cada familia) y 467 se destinaron a la conservación. El Parque Guanacaste, fue comprando estás tierras, gran parte de lo que fueron inicialmente tierras cedidas a parceleros, actualmente forman parte del ACG.

Siendo esta la comunidad más cercana al parque, en los últimos años, el acercamiento entre el parque y la comunidad se ha realizado como una estrategia para luchar contra los incendios forestales; la capacitación por parte del parque y la incorporación de voluntarios de la comunidad han mejorado sustancialmente la relación. Mediante las entrevistas realizadas a los pobladores, se observa optimismo la relación entre el parque y la comunidad; ya el este último ha sido visto por algunos como un gran competidor al integrar fincas agrícolas y ganaderas al parque nacional; limitando de esta manera el acceso al recurso tierra. 
Lilliam Quirós-Arias. Tourism and territory in natural protected areas - the case of Santa Rosa National Park: from national monument to the conservation of the tropical forest, Guanacaste Conservation Area, Costa Rica

\subsection{Puerto Soley y el Jobo comunidades costeras}

Puerto Soley y el Jobo forman parte de las comunidades ubicadas en la línea de costa. Ambas integraron haciendas ganaderas que, posteriormente fueron expropiadas y repartidas por el ITCO-INDER. Sobre estas áreas, se refleja una gran presión por el desarrollo turístico, la presencia de playas de gran belleza ha ocasionado la llegada de inversionistas extranjeros $\mathrm{y}$, consecuentemente, la venta de tierras por parte de los parceleros. La construcción de infraestructura hotelera y de servicios turísticos amenaza a los espacios costeros y la permanencia de estas comunidades.

\subsection{La Cruz pueblo de paso - fronterizo - nodo secundario de distribución}

El centro urbano La Cruz de Guanacaste es el centro principal de servicios de este cantón fronterizo de $1.383 \mathrm{~km}^{2}$; el $50 \%$ de la superficie se encuentra bajo protección por parte del SINAC. Su población total es de 19.181 habitantes (INEC, 2011), con un porcentaje de analfabetismo 6,23\%. En el Índice de Desarrollo Social ocupa el puesto 69 de los 81 cantones de Costa Rica. Su centro, poblado principal La Cruz, se ubica a 20 kilómetros de la frontera norte, siendo que el turismo de "visaje" se observa como una actividad frecuente. Por su parte, la oferta de servicios dirigidos al turismo es escasa, en el centro, poblado principal, se registra una mínima oferta de hoteles y restaurantes.

\subsection{Punto intermedio de distribución: Ciudad Blanca - Liberia}

Liberia es el centro poblado principal y capital de la provincia de Guanacaste, como ciudad intermedia ofrece servicio de gran importancia para el turismo ${ }^{4}$. El aeropuerto internacional Daniel Oduber Quirós está próximo a esta ciudad ${ }^{5}$; a su vez, Liberia se ubica a 30 kilómetros del Parque Nacional Santa Rosa, de ahí es posible desplazarse, en menos de una hora, con buenas rutas de acceso, a las playas y las áreas de conservación

3 Extranjeros que deben abandonar el país donde residen al menos por 48 horas, para esto cruzan la frontera del país y con esto validan su pasaporte para permanecer en el país donde residen de manera legal.

4 Según datos del ICT (2014), Guanacaste es la unidad de planeamiento turístico que tiene mayor número de habitaciones 5 estrellas, con un $37.8 \%$.

5 Este aeropuerto fue inaugurado en el año 1999, recibe turistas que se desplazan directamente hacia los principales centros turísticos de la provincia de Guanacaste, sin transitar por la capital del país. Este aeropuerto dinamizó la actividad turística de la provincia de Guanacaste, dada la gran diversidad de playas y paisaje costero. 
más importantes como el PNSR y el Parque Rincón de la Vieja. Esto explica, en parte, el escaso desarrollo de la oferta turística que se da en las cercanías de las comunidades aledañas al PNSR.

\section{El turismo, el Parque Nacional Santa Rosa y las comunidades locales \\ El Área de Conservación Guanacaste posee desarrollo turístico inci-} piente, con recursos de tipo natural, siendo el Parque Nacional Santa Rosa el de mayor jerarquía. En general, en el ACG algunos sectores son de libre acceso al turismo, mientras que otros son de acceso restringido, destinados a la investigación y conservación. En el cuadro 4, se sintetizan los sectores de interés turístico, educación e investigación.

\section{Cuadro 4. Costa Rica. Sectores de Interés turístico en Parque Nacional} Santa Rosa y Área de Conservación Guanacaste. 2014

\begin{tabular}{|l|l|}
\hline \multicolumn{2}{|c|}{ Sectores de interés turístico, educación e investigación } \\
\hline Sector Santa Rosa* & $\begin{array}{l}\text { Se localiza el Museo Histórico La Casona Santa Rosa, principal } \\
\text { atractivo turístico. El sector Playa Naranjo se ubica en este sector. }\end{array}$ \\
\hline Sector Murciélago* & $\begin{array}{l}\text { Gran riqueza de bosque seco, playa, manglar y posee una gran } \\
\text { importancia geológica, los cerros de la Península Santa Elena, las } \\
\text { tierras más antiguas de Costa Rica. }\end{array}$ \\
\hline Sector las Pailas & $\begin{array}{l}\text { Rincón de la Vieja, es el más visitado del ACG. Combina } \\
\text { la observación del cráter activo del volcán con los paisajes } \\
\text { circundantes así como la flora y la fauna. }\end{array}$ \\
\hline Sector Junquillal & $\begin{array}{l}\text { Se localiza el Refugio Nacional de Vida Silvestre Bahía Junquillal, } \\
\text { ubicado en la costa, y que ofrece una gran riqueza biológica. }\end{array}$ \\
\hline Sector Santa María & $\begin{array}{l}\text { Forma parte del Parque Rincón de la Vieja, de gran belleza } \\
\text { escénica, riqueza biológica y manifestaciones volcánicas. }\end{array}$ \\
\hline $\begin{array}{l}\text { Estación Experimental } \\
\text { Forestal Horizontes }\end{array}$ & $\begin{array}{l}\text { Observación de bosque seco tropical, observación de aves, } \\
\text { especies forestales y práctica de ciclismo de montaña. }\end{array}$ \\
\hline Sector marino & $\begin{array}{l}\text { Ubicado en el Golfo Papagayo, protección de ecosistema marino y } \\
\text { uso turístico, buceo recreativo y surfing. }\end{array}$ \\
\hline
\end{tabular}

Fuente: Elaborado a partir de información Área de Conservación Guanacaste, 2014.

Nota. * Estos dos sectores están dentro del Parque Nacional Santa Rosa, los demás forman parte del Área de Conservación Guanacaste. 
Lilliam Quirós-Arias. Tourism and territory in natural protected areas - the case of Santa Rosa National Park: from national monument to the conservation of the tropical forest, Guanacaste Conservation Area, Costa Rica

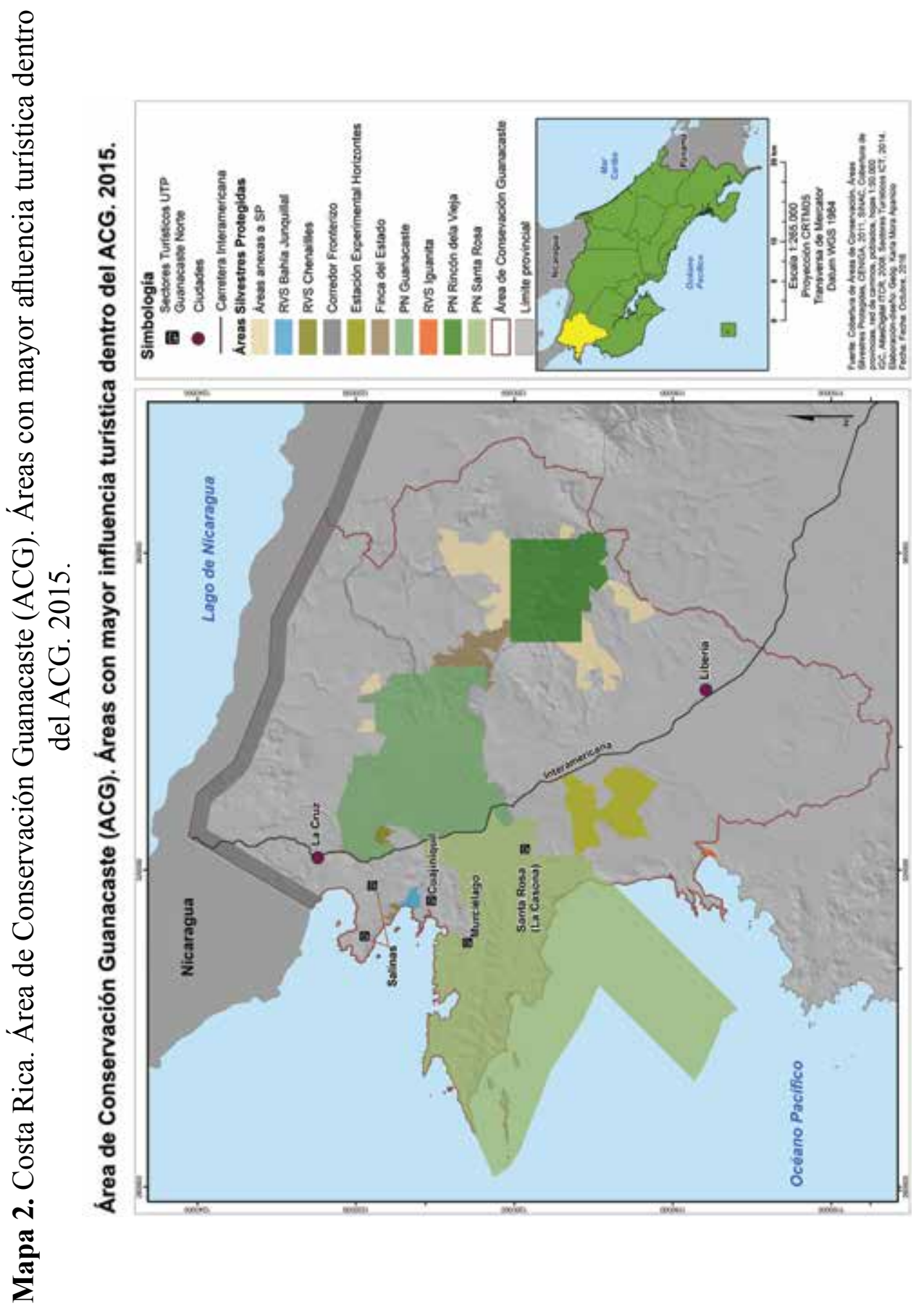

112 Revista Geográfica de América Central No Especial ISSN 1011-484X, I Semestre 2017, pp. 91-136 
En el Parque Nacional Santa Rosa se ubica el Programa de Ecoturismo, el cual promueve y monitorea la actividad para el área de conservación. La visitación del ACG es variada, siendo las áreas de mayor visitación el Parque Nacional Rincón de la Vieja, el Parque Nacional Santa Rosa y la Reserva de Vida Silvestre Junquillal, mientras que la visitación en el Parque Guanacaste y la Estación Experimental Horizontes es casi nula.

Asimismo, es de gran importancia el Programa de Educación del ACG creado en 1986, que atiende 53 centros educativos con aproximadamente 2500 estudiantes, bajo tres programas; educación biológica, biosensibilización marina y educación ambiental. Este programa ha generado una serie de productos didácticos para la educación, entre ellos: bosque seco virtual, boletín rothshildia y páginas de especies, todas ellas accesibles en línea. "Al Dr. Daniel Janzen ${ }^{6}$, por haber tenido una visión a futuro y enseñarnos a leer esos grandes libros que tenemos por bosques" (ACG, Compendio de Actividades de Educación Ambiental para Escolares de II Ciclo, 2011).

El turismo en Guanacaste nace en los años ochenta como destino turístico local, teniendo como principales atractivos playas, áreas protegidas y pesca deportiva; con grandes desarrollos en algunos sectores y escasos en otras áreas, como es el caso del ACG que se clasifica como un desarrollo turístico incipiente, con atractivos de tipo natural. Según la metodología del Inventario Turístico aplicado a la Unidad Turística Guanacaste Norte (TT Argos, 2008): el 55\% del inventario turístico se clasifica en la Jerarquía 1, sin mérito suficiente para motivar desplazamiento turístico; $37 \%$ Jerarquía 2 , posee algún llamativo para atraer visitantes y $17 \%$ Jerarquía 3, atractivos con rasgos excepcionales, es el caso del Parque Nacional Santa Rosa.

Asimismo, Blanco (2007), clasifica los atractivos naturales y culturales de acuerdo con su importancia como se observa en el cuadro 5.

6 El Dr. Daniel Janzen ecologista tropical y profesor Universidad de Pennsylvania, miembro fundador del Instituto Nacional de Biodiversidad (INBIO), con premios ha contribuido a compra de tierras y consolidar el Área de Conservación Guanacaste Liderado el Inventario más de 500,000 especies, y sus publicaciones son conocidas en todo el mundo; entre sus más sobresalientes aportes están: Historia Natural de Costa Rica, El Futuro de la Ecología Tropical y Parque Nacional de Guanacaste: Restauración Ecológica y Biocultural Tropical. En noviembre 2014, el Dr Janzen y a la Dra. Winnie Hallwalchs, obtuvieron el Premio Blue Planet Price por todo su enorme esfuerzo en ayudar a construir hoy lo que es ACG. Un esfuerzo gigantesco reconocido mundialmente. 
Lilliam Quirós-Arias. Tourism and territory in natural protected areas - the case of Santa Rosa National Park: from national monument to the conservation of the tropical forest, Guanacaste

Conservation Area, Costa Rica

Cuadro 5. Costa Rica. Cantón de La Cruz. Atractivos naturales y culturales del cantón de La Cruz, Guanacaste. 2014

\begin{tabular}{|l|c|l|}
\hline \multicolumn{1}{|c|}{ Atractivo } & Categoría & \multicolumn{1}{c|}{ Actividades } \\
\hline Parque Nacional Santa Rosa & III & $\begin{array}{l}\text { Senderismo, flora y fauna, } \\
\text { cabalgatas, bicicleta y descanso }\end{array}$ \\
\hline Museo Histórico La Casona & III & Historia \\
\hline Refugio de Vida Silvestre Junquillal & II & Senderismo y natación \\
\hline Volcán Orosi & II & Senderismo, flora y fauna \\
\hline $\begin{array}{l}\text { Playas Cuajiniquil, Puerto Soley, } \\
\text { Jobo, La Rajada, Copal }\end{array}$ & I & Deportes acuáticos, pesca y descanso \\
\hline $\begin{array}{l}\text { Ríos Sapoa, Hacienda Ánimas, } \\
\text { Sábalo y Mena }\end{array}$ & I & Pesca, descanso \\
\hline Isla Bolaños & I & Observación de aves \\
\hline Corredor Biológico Mesoamericano & I & Ríos, flora y fauna \\
\hline
\end{tabular}

Fuente: A partir de Blanco, M (2007, p.46) y trabajo de campo 2014.

Además, se realizan actividades culturales programadas como las Fiestas Patronales con recursos como comidas típicas, caballistas, toros y música.

Por su parte, el ICT, en el Plan Nacional de Turismo Sostenible de Costa Rica, 2010 - 2016, señala que el área posee un atractivo natural de alta jerarquía. Este estudio divide la Unidad Turística Guanacaste Norte en tres sectores:

a. Salinas. El centro turístico corresponde a La Cruz, los poblados son pequeños y dispersos como los casos de Soley y el Jobo y con pocos servicios, el desarrollo turístico es incipiente.

b. Cuajiniquil. En todo el sector existe como poblado Cuajiniquil, el resto del poblamiento corresponde a viviendas aisladas en fincas; su desarrollo turístico es nulo y podría ligarse a La Cruz y Liberia como centros turísticos.

c. Parque Nacional Santa Rosa. Comprende el litoral y tierras interiores del Parque Nacional Santa Rosa.

A excepción de otras áreas, el desarrollo urbano no se ubica sobre la línea de costa, sino sobre las vías de interconexión; e históricamente, son centros de producción agrícola y ganadera, como Liberia y La Cruz. 
La ocupación hacia las zonas costeras se debe a un proceso de avance de la frontera agrícola, favoreciendo la ubicación de poblados y comunidades menores sobre vías secundarias, las cuales han permanecido en relativo aislamiento.

Según ICT (2007), "los atractivos de esta unidad no constituyen un eje unificado en virtud de la existencia del Parque Nacional Santa Rosa, los atractivos situados hacia el norte generan un espacio turístico con influencia directa de la ciudad de La Cruz; los atractivos de la porción sur forman un eje relacionado con la ciudad de Liberia. El Parque Nacional Santa Rosa que está incluido dentro de este sector, se establece como un punto de alta importancia no solamente para el sector sino para el resto de la unidad" (p.92). A partir del nodo Liberia, se genera el acceso al Parque Nacional Santa Rosa, Cuajiniquil y Junquillal y de aquí por rutas secundarias hasta Bahía Salinas; La Cruz funciona como un nodo secundario para el acceso a la zona de Bahía Salinas. (Véase Mapa 3).

Según datos ICT (2012), "el nodo principal de Liberia funciona como un centro de distribución a partir de la Ruta Nacional 1 (Carretera Interamericana), tanto para el turismo que viene de otras Unidades de Planeamiento (Valle Central, Llanuras del Norte o Pacífico Central), así como para el turismo internacional que se desplaza desde Nicaragua.

Es claro que, a pesar de su temprana creación (1971), el PNSR no generó un desarrollo turístico, para que esto sea posible es necesaria la política pública en su intencionalidad e impulso por generar y promover la inversión privada, situación que está ocurriendo con el último plan de desarrollo turístico $2010-2016$. 
Lilliam Quirós-Arias. Tourism and territory in natural protected areas - the case of Santa Rosa National Park: from national monument to the conservation of the tropical forest, Guanacaste Conservation Area, Costa Rica

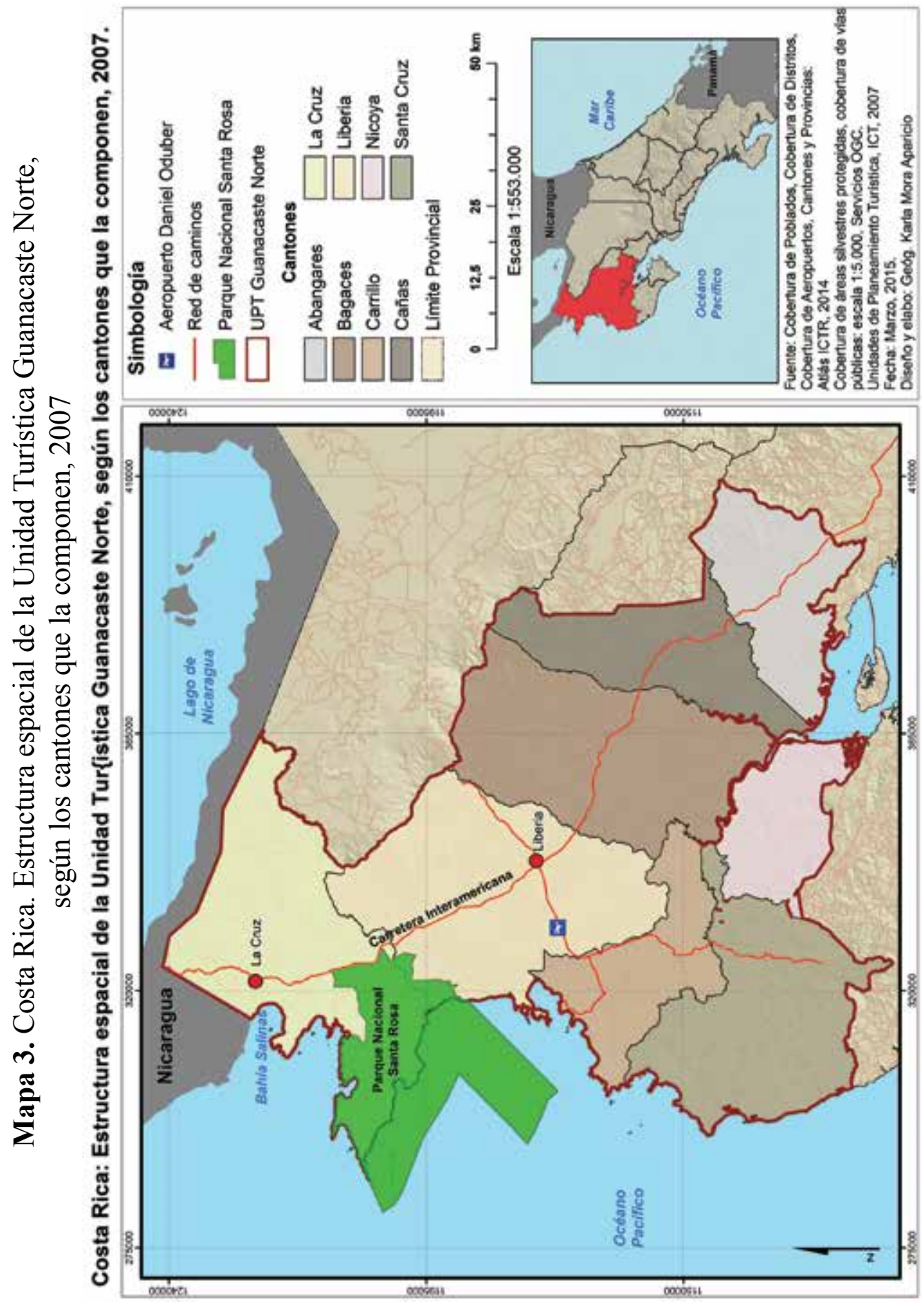

116 Revista Geográfica de América Central No Especial ISSN 1011-484X, I Semestre 2017, pp. 91-136 


\subsection{Visitación turística y dinámica de la actividad}

Como se puede observar el gráfico 2, la visitación turística en las áreas naturales protegidas de Costa Rica ha experimentado un aumento constante desde el año 2000, con declives en el año 2004 y 2009.

Figura 4. Costa Rica. Visitación total de turirstas a las áreas protegidas, período 2000-2012

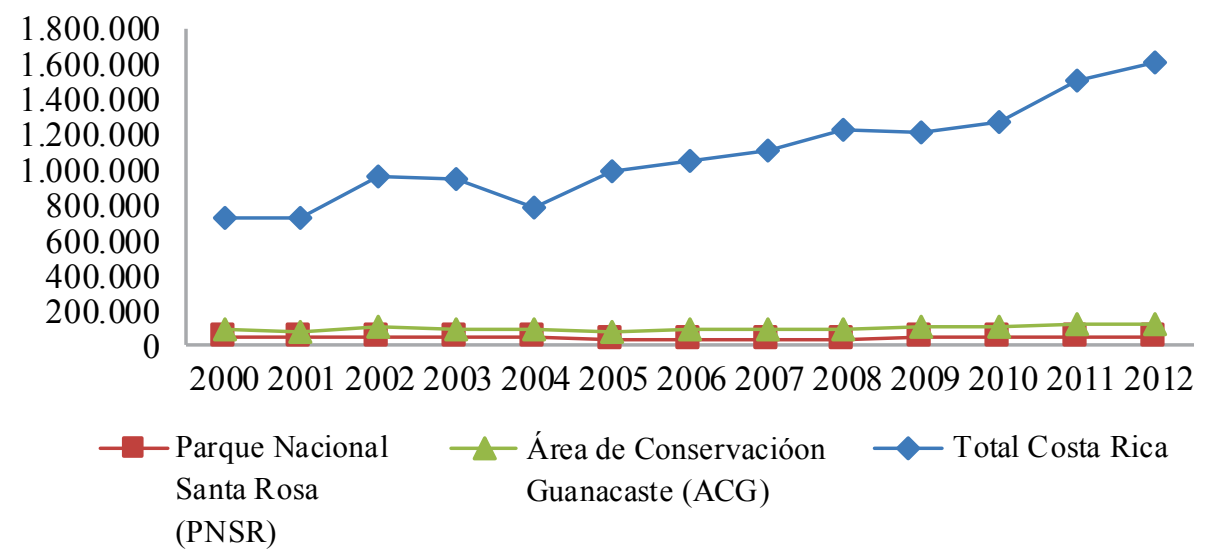

Fuente: Elaboración propia, 2013, a partir de los datos del Programa de Ecoturismo, ACG, 2012.

El PNSR presenta la particularidad de recibir un mayor número de visitantes nacionales (cuadro 6), dado que el recurso principal, "Monumento Casona de Santa Rosa", prevalece en la memoria costarricense como un hito histórico que se estudia desde los niveles básicos de educación. Mientras que, como se observa en el cuadro 5, el Parque Nacional Rincón de la Vieja es visitado mayormente por turistas extranjeros. Otras áreas, dentro de la ACG, reciben poca visitación como es el caso del Parque Guanacaste y la Estación Biológica Horizontes. Según una entrevista realizada a Guadalupe Rodríguez, funcionara PNSR; "los visitantes establecen relación entre los dos parques más visitados, PNSR y Parque Nacional Rincón de la Vieja (PNRV), cuando el visitante llega se da la información correspondiente al PNSR y de las otras áreas de conservación donde es posible visitar, ya que el ACG es visto como un sistema. El Parque Guanacaste lo visitan grupos organizados interesados en temas biológicos, en la Estación Maritza se observan principalmente petroglifos, cacao, pitilla y bosque”. 
Lilliam Quirós-Arias. Tourism and territory in natural protected areas - the case of Santa Rosa National Park: from national monument to the conservation of the tropical forest, Guanacaste

Conservation Area, Costa Rica

Cuadro 6. Costa Rica. Área de Conservación Guanacaste. Visitación a parques nacionales según procedencia, 2013

\begin{tabular}{|l|c|c|c|c|c|}
\hline \multicolumn{1}{|c|}{ Parques ACG } & Nacionales & $\mathbf{( \% )}$ & Extranjeros & $\mathbf{( \% )}$ & Total \\
\hline Parque Nacional Santa Rosa & 25076 & $\mathbf{7 1 . 5 8}$ & 9959 & $\mathbf{2 8 . 4 2}$ & 35035 \\
\hline Parque Nacional Rincón de la Vieja & 12771 & $\mathbf{2 2 . 3 8}$ & 44312 & $\mathbf{7 7 . 6 2}$ & 57083 \\
\hline
\end{tabular}

Fuente: Área de Conservación Guanacaste, 2013.

Los turistas internacionales provienen mayoritariamente de Estados Unidos, Francia, Alemania y Canadá, como se observa el mapa 4.

En el caso de la visitación nacional, un alto porcentaje de los visitantes provienen de Guanacaste (41\%), San José (28\%) y Alajuela (13\%), la mayor visitación se da en la temporada de vacaciones escolares, Semana Santa, fin de año, navidad y, en general, en la época seca; en la época lluviosa los grupos de escuela y colegios son los que visitan el área. Los días lunes, martes y miércoles la visitación es baja; sin embargo, los lunes cuando el Parque Nacional Rincón de la Vieja (PNRV) está cerrado los turistas visitan el PNSR.

En días de baja visitación reciben en promedio 20 personas; durante los fines de semana reciben 50 personas al día y en fin de semana largo, la visitación es mayor. Según el dato suministrado por Guadalupe Rodríguez, Funcionario del PNSR, este año (2014) dicha actividad la visitación al sector Santa Rosa ha sido histórica con 4126 personas, el doble que año anterior; esto debido a la realización de la "Campaña de senderos históricos" y por efecto de la sequía en Guanacaste que motiva a la gente a salir de sus casas.

La permanencia en el parque es de aproximadamente dos horas para los nacionales quienes visitan, principalmente, la Casona Santa Rosa, el Monumento a los Héroes y El Sendero Natural Indio Desnudo. Normalmente, la visita a la Casona es guiada. Los extranjeros además de visitar estos atractivos, visitan los senderos que van hacia la playa y a los miradores; sobre todo Playa Naranjo, que a pesar de no tener buen acceso es posible llegar en carro doble tracción en época seca. La playa Nancite está cerrada al público ya que se ha destinado sólo para investigación. Los caminos de acceso para las playas en el PNSR son en general malos, difíciles de transitar; en época lluviosa, incluso no es posible llegar ni en carro doble tracción. 
Lilliam Quirós-Arias. Turismo y territorio en áreas naturales protegidas, Parque Nacional Santa Rosa: del monumento nacional a la conservación del bosque tropical seco, Área de Conservación Guanacaste, Costa Rica

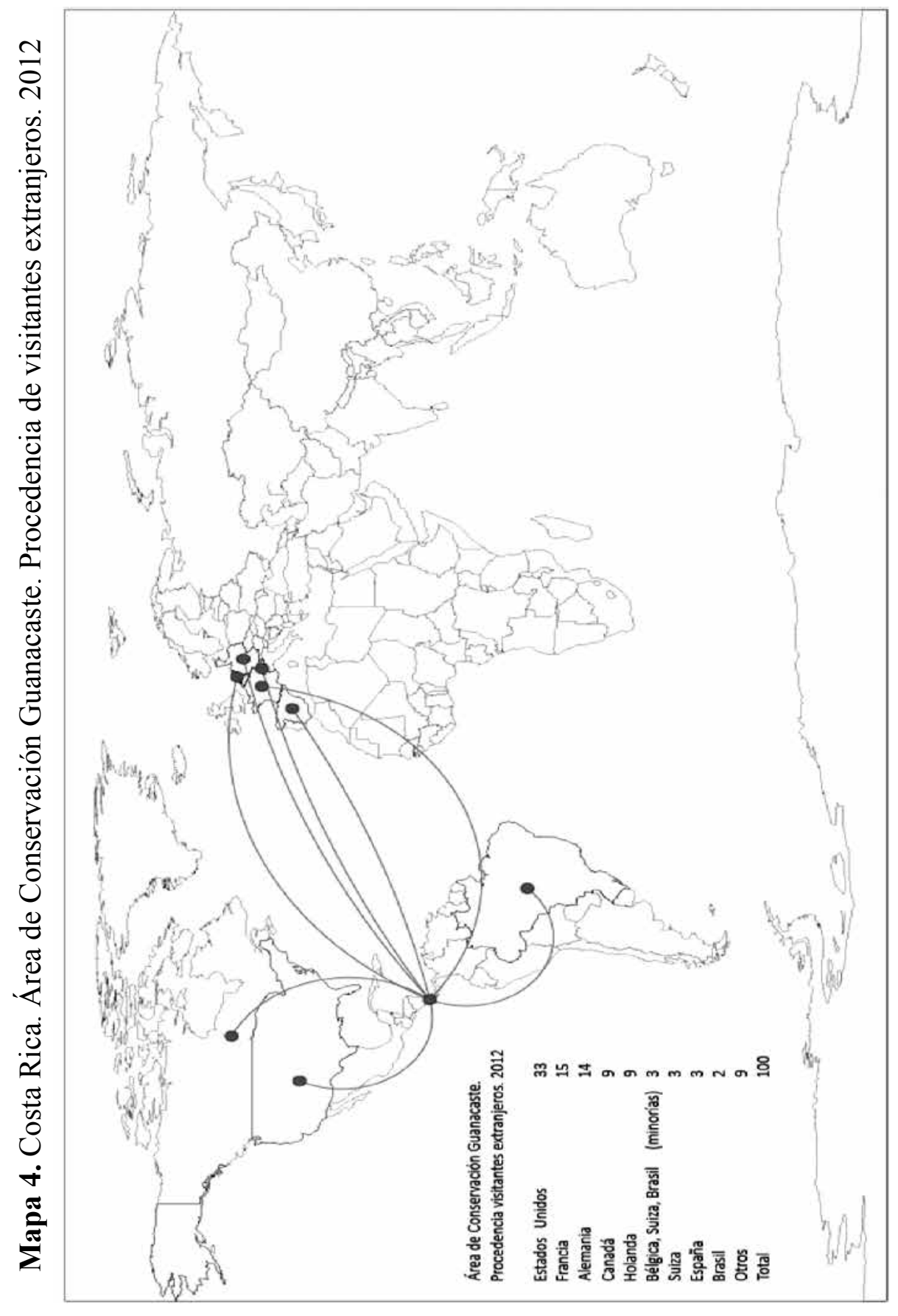

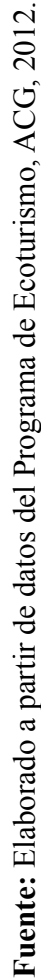


En playa Naranjo se práctica el surf, de ahí que la visitación depende del comportamiento de las mareas. Además, es posible acampar, se tiene un espacio con capacidad para 50 personas; la falta de agua potable es un problema, por lo que cada campista debe llevar su propia agua, esto crea dificultades; a pesar de ello los visitantes se quedan de 2 a 3 días. Se proyecta eliminar el camping en este sitio; aunque hay senderos, no es un sitio apto para familias y niños. Cuando la gente ingresa al parque, y quieren visitar estas playas, se les explica sobre la oferta turística que hay alrededor, especialmente Playa Junquillal y el Sector Murciélago, sector en el cual el principal recurso son las playas, visitadas especialmente por turismo nacional; algunas de ellas son la playa Hachal (5 km), Bahía Santa Elena $(8 \mathrm{~km})$ y Playa Blanca $(17 \mathrm{~km})$, con caminos de difícil acceso y en condiciones adecuadas. (Véase figura 5).

La capacidad de carga del PNSR no representa un problema, el área es amplia y la presión por visitación no es considerada un problema en este momento. Actualmente, en el PNSR se están trabajando dos proyectos importantes: a) la construcción de un Sendero Universal para personas con limitaciones físicas; se ha recolectado el dinero con el apoyo de la empresa privada para tal fin y b) en la articulación de la comunidad mediante el Proyecto de Servicios No esenciales, el cual está en fase inicial. Se espera que la comunidad ofrezca algunos de los servicios bajo esta categoría, como área de acampar, tienda, transporte hacia la playa, soda, entre otros. 
Figura 5. Costa Rica. Visitación Parque Nacional Santa Rosa respecto al ACG.2012

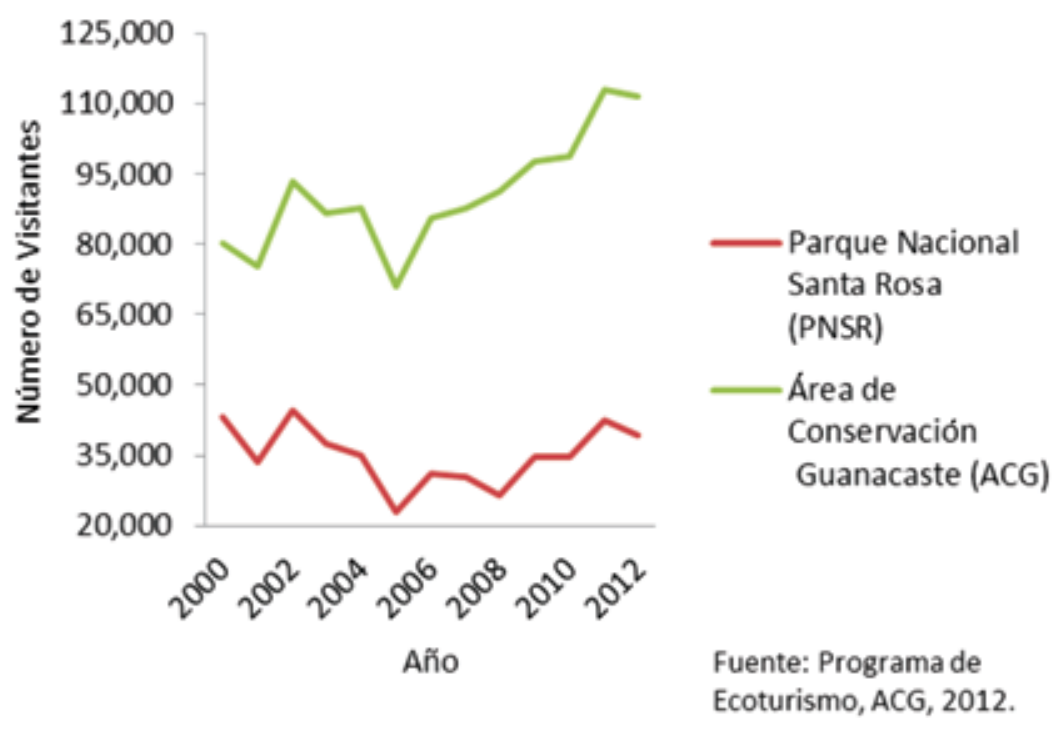

Fuente: Elaboración propia a partir del datos del Programa de Ecoturismo de ACG, 2012.

\subsection{Estructura y distribución de la oferta turística}

En las dos comunidades cercanas al PNSR, Cuajiniquil y Colonia Bolaños, la oferta turística es escasa; en la comunidad Cuajiniquil, mediante recorrido de campo, se comprobó que existen tres hoteles y dos restaurantes; Hotel Cabinas Cuajiniquil (2011), Hotel Santa Elena Lodge (2006) y Cabinas Manglar (1994) con tres, diez y cuatro habitaciones respectivamente. A excepción de Cabinas Manglar los otros dos hoteles son de fundación reciente. En la comunidad Colonia Bolaños no se ubicaron servicios de hospedaje, únicamente funcionan dos restaurantes inaugurados en 2014.

En las comunidades aledañas, el centro poblado principal de $\mathrm{La}$ Cruz, El Jobo, Puerto Soley, Sonzapote y La Garita, la oferta turística es escasa pero variada. Como es de esperar, gran parte de los hoteles se ubican en La Cruz y en las comunidades costeras -El Jobo y Puerto Soley-. En el área hay 17 hospedajes, para un total 711 habitaciones. Como puede verse en el cuadro 8, recientemente se inauguró un hotel de 447 habitaciones ubicado en la comunidad costera El Jobo, área que según el ICT 
(2012), está destinada para el turismo concentrado. Esto es evidencia que la oferta turística se ha ido incrementando en la zona costera.

Por su parte, la oferta de servicios dirigidos al turismo es escasa; en el centro poblado principal, se registra una oferta básica de servicios para el turismo, especialmente restaurantes. Según los datos del ICT (2012), se registran 12 hoteles, de los cuales dos cuentan con declaratoria turística y ninguno de ellos cuenta con certificación de sostenibilidad turística. En el recorrido de campo se documentó la existencia de cinco hospedajes más, de reciente construcción, en total 17, distribuidos en todo el cantón. (Véase cuadro 7).

Cuadro 7. Costa Rica. La Cruz, Guanacaste. Oferta de hospedaje en el centro poblado principal de La Cruz y alrededores, 2014

\begin{tabular}{|l|c|l|c|}
\hline \multicolumn{1}{|c|}{ Nombre } & $\begin{array}{c}\text { No. } \\
\text { habitaciones }\end{array}$ & \multicolumn{1}{|c|}{ Nombre } & $\begin{array}{c}\text { No. } \\
\text { habitaciones }\end{array}$ \\
\hline Hotel Dreams Las Mareas* & 447 & Hotel Amalia's Inn & 9 \\
\hline Hotel Bolaños Bay Resort & 72 & $\begin{array}{l}\text { Cabinas Peñas Blancas Bar y } \\
\text { Restaurant }\end{array}$ & 9 \\
\hline Cabinas Santa Rita & 38 & $\begin{array}{l}\text { Hotel Bar Y Restaurante Faro } \\
\text { Del Norte }\end{array}$ & 8 \\
\hline Ecoplaya Beach Resort & 36 & Cabinas Marifel & 7 \\
\hline Hotel Bello Vista & 20 & Finca Cañas Castilla & 6 \\
\hline Hotel Colinas Del Norte & 15 & Tierra Madre Eco Lodge Hotel & 5 \\
\hline La Mirada Hotel & 12 & Cabinas Manglar & 4 \\
\hline Hotel Blue Dream & 10 & Hotel Cabinas Cuajiniquil & 3 \\
\hline Hotel Santa Elena Lodge & 10 & \multicolumn{1}{|c|}{$\mathbf{7 1 1}$} & \\
\hline Total & & \multicolumn{1}{|c|}{} \\
\hline
\end{tabular}

Fuente: Elaborado a partir de ICT (2014), y recorrido de campo.

*Este hotel fue inaugurado en noviembre del 2014.

Para el área de estudio, según ICT (2007), "En términos generales, las instalaciones turísticas están básicamente asociadas a los atractivos puntuales en la línea de costa. Todavía no se desarrolla una línea sólida de complementariedad de otros productos, complementos que establezcan circuitos de desplazamiento y potencien la diversificación de actividades potenciales para la práctica del turismo" (p.108). Asimismo, según esta misma fuente, "los atractivos naturales están funcionando 
como complemento de esa primaria actividad de sol y playa, los atractivos relacionados con la línea de costa sucede en el eje de Bahía Salinas y Punta Descartes, siendo atractivos básicamente de tipo 3 que reflejan buenas condiciones para el desarrollo de la actividad turística" (p.92).

Según el recorrido de campo, proyectos orientados hacia el agroturismo y turismo alternativo y algunos servicios turísticos como hoteles y cabinas se localizan en lugares distantes de los principales desarrollos turísticos. En este momento, se está reactivando la Cámara de Turismo del cantón de La Cruz que tiene entre sus objetivos integrar estos proyectos en un circuito turístico, de manera que beneficie otras comunidades hasta ahora alejadas de la actividad.

En el mapa 5, se muestra la distribución territorial de la oferta turística de hospedaje (cabinas y hoteles), restaurantes y sodas, proyectos agroturísticos y principales atractivos turísticos entre estas playas ubicadas alrededor del Parque Nacional Santa Rosa. La distribución de estos recursos y oferta turística denotan una concentración de la misma en la zona costera, y la ubicación de algunos proyectos novedosos en áreas de montaña y zonas fronterizas. El Parque Nacional Santa Rosa, por su parte forma una especie de barrera entre estas comunidades y la ciudad de Liberia. 
Lilliam Quirós-Arias. Tourism and territory in natural protected areas - the case of Santa Rosa National Park: from national monument to the conservation of the tropical forest, Guanacaste Conservation Area, Costa Rica

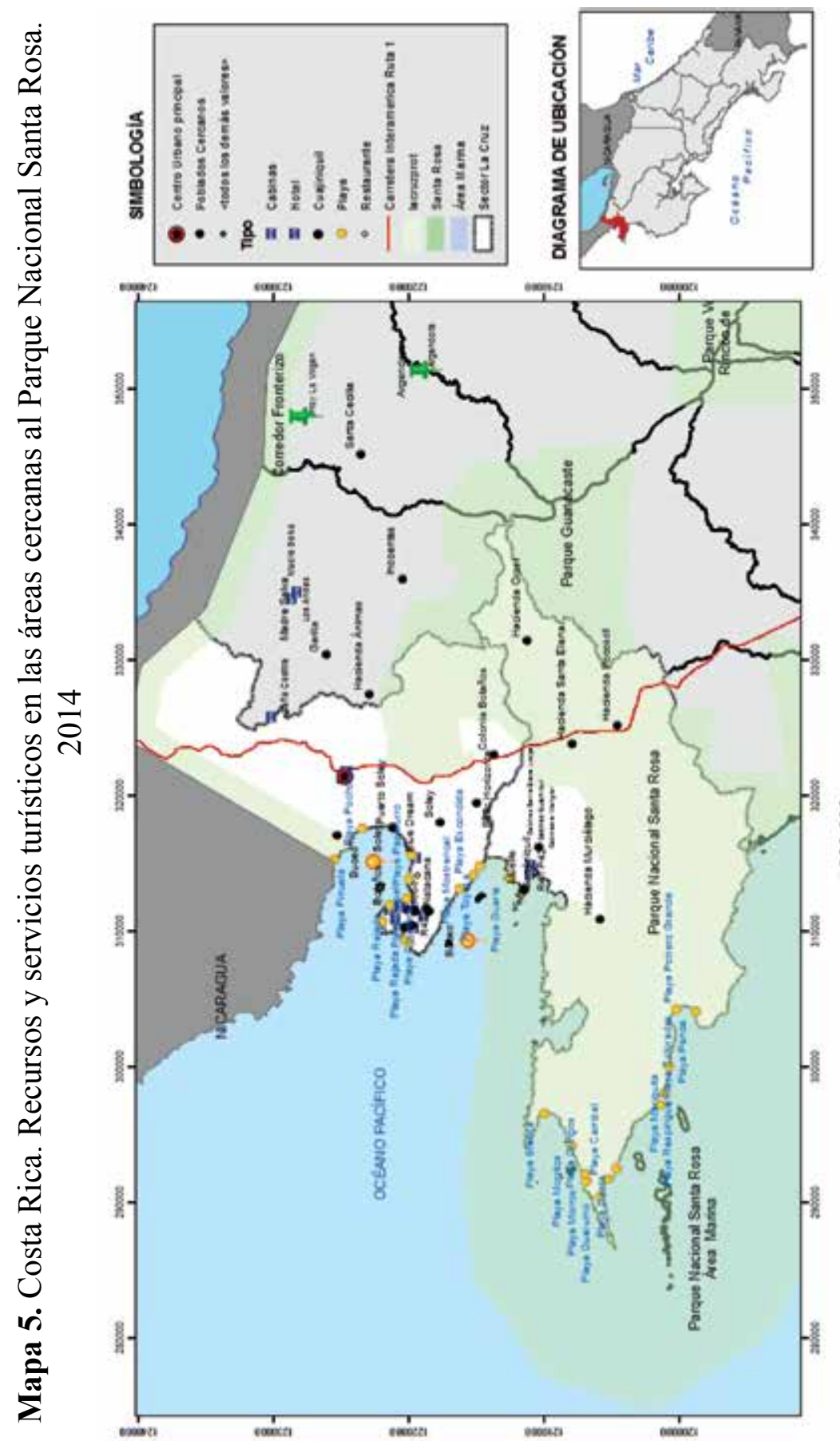


Como se desprende de la distribución de los recursos turísticos, estos se relacionan principalmente con los de sol y playa; siendo que se articulan alrededor del Parque Nacional Santa Rosa, en el cantón de La Cruz, Guanacaste. En el cuadro 8 y representados en el Mapa 5, se enumeran los principales recursos y la oferta turística que movilizan la visitación al cantón. Evidenciando que el PNSR, es el recurso principal de atracción turística y de ahí los visitantes se desplazan hacia otros destinos.

Cuadro 8. Costa Rica. La Cruz, Guanacaste. Oferta turística alrededor del Parque Nacional Santa Rosa, cantón de La Cruz y alrededores, 2014.

\begin{tabular}{|l|l|l|l|}
\hline \multicolumn{1}{|c|}{ Cabina } & \multicolumn{1}{|c|}{ Hoteles } & Restaurante y sodas & \multicolumn{1}{|c|}{ Atractivos turísticos } \\
\hline Bolaños & Amalia's Inn & El Pirata & Mirador El recreo \\
\hline Caña Castilla & Bella Vista & El Rancho & Muelle Cuajiniquil \\
\hline Marifel & Blue Dreams & Marakabú & Playa Papaturro \\
\hline Santa Rita & Bolaños & Pescadería Goal & Playa Rajada \\
\hline Mirador Pta. Descartes & Dreams Las Mareas & Pizzería & Playa Soley \\
\hline Cuajiniquil & Ecoplaya & Plaza Copal & \\
\hline & El Manglar & Punta Descartes & Poblados cercanos \\
\hline Proyecto Agroturísticos & El Recreo & Soda Male & Cuajiniquil \\
\hline Vainilla Argendora & Foro del Norte & Soda Thelma & La Garita \\
\hline La Virgen, granos básicos & Hospedaje del Sol & & La Gloria \\
\hline & La Mirada & & La Virgen \\
\hline & Madre Selva & & Los Andes \\
\hline & Santa Elena Lodge & & Natacana \\
\hline
\end{tabular}

Fuente: Trabajo de campo, 2013-2014.

La política del desarrollo, según ICT (2007), debe fundamentarse en la aplicación del concepto de desarrollo concentrado ${ }^{7}$ en centros turísticos y áreas de desarrollo turístico limitado. La dinámica del sector sugiere el establecimiento de un único centro de desarrollo turístico (CT) Puerto Soley- El Jobo. Este espacio se caracterizará por un desarrollo turístico con ofertas de nivel de calidad medio dirigido a segmentos, igualmente,

7 Sánchez, A. (2005). Los espacios geográficos delimitados por centros de turismo tienen la función de identificar los sitios donde potencialmente se puede desarrollar productos turísticos comercialmente exitosos hacia donde se deben dirigir inversiones públicas como carreteras, aeropuertos, acueductos rurales, puentes, telecomunicaciones, tendido eléctrico, etcétera. También, permiten seleccionar sitios de interés para la comunidad y áreas de protección absoluta de la naturaleza para el mejoramiento del paisaje natural. 
medios para actividades de sol y playa, deportes de playa, descanso y actividades náuticas. Se concentra en la utilización de las playas Papaturro, Copal, Coyotera, Rajada y el Jobo y Rajada oeste como el principal espacio de desarrollo por la calidad de la misma, y de forma secundaria, en Pochote y Puerto Soley (p.120-123).

El mapa 6, muestra la zonificación turística para la zona costera, de acuerdo con el Plan General de Uso de la Tierra y Desarrollo Turístico para Guanacaste Norte, en el cual se delimitan áreas núcleo para atracciones turísticas, área mixta para turismo y comunidad, área planificada para el desarrollo turístico y área para desarrollo controlado. Esto indica que la actividad turística seguirá creciendo en los próximos años, bajo el esquema de sol y playa, para lo cual los recursos costeros serán decisivos en este desarrollo.

\section{Experiencias de turismo sostenible en los alrededores del Parque Nacional Santa Rosa, Guanacaste}

Algunas experiencias de turismo en el cantón de La Cruz, sugieren que se está dando un desarrollo de proyectos alternativos como posibilidades de turismo que, de alguna manera, podrían integrarse a la oferta de sol y playa existente. El Turismo a pequeña escala, los encadenamientos productivos, la utilización de materiales locales, la producción agrícola orgánica, la regeneración de potreros y el aprovechamiento del paisaje y recursos del bosque, entre otras características, son observables en estas experiencias.

\subsection{Cabinas Caña Castilla}

Las Cabinas Caña Castilla es un proyecto ubicado en Sonzapote de La Cruz, a 10 kilómetros de la frontera norte de Costa Rica; inaugurado en el año 1994, propiedad de un matrimonio suizo. El área total del proyecto es de 59 hectáreas, donde construyeron sus cabañas equipadas para dos a cuatro personas, con estadía promedio de dos a tres días. Los visitantes provienen, en su mayoría, de Suiza, Canadá, Polonia y otros países europeos. Ofrecen los servicios de hospedaje, alimentación, senderos, cabalgatas, observación flora y fauna y realizan tours a las playas. Además, la demanda la complementa un turismo muy particular que se denomina turismo de visaje, dada la cercanía del proyecto con la frontera norte de Costa Rica. 
Lilliam Quirós-Arias. Turismo y territorio en áreas naturales protegidas, Parque Nacional Santa Rosa: del monumento nacional a la conservación del bosque tropical seco, Área de Conservación Guanacaste, Costa Rica

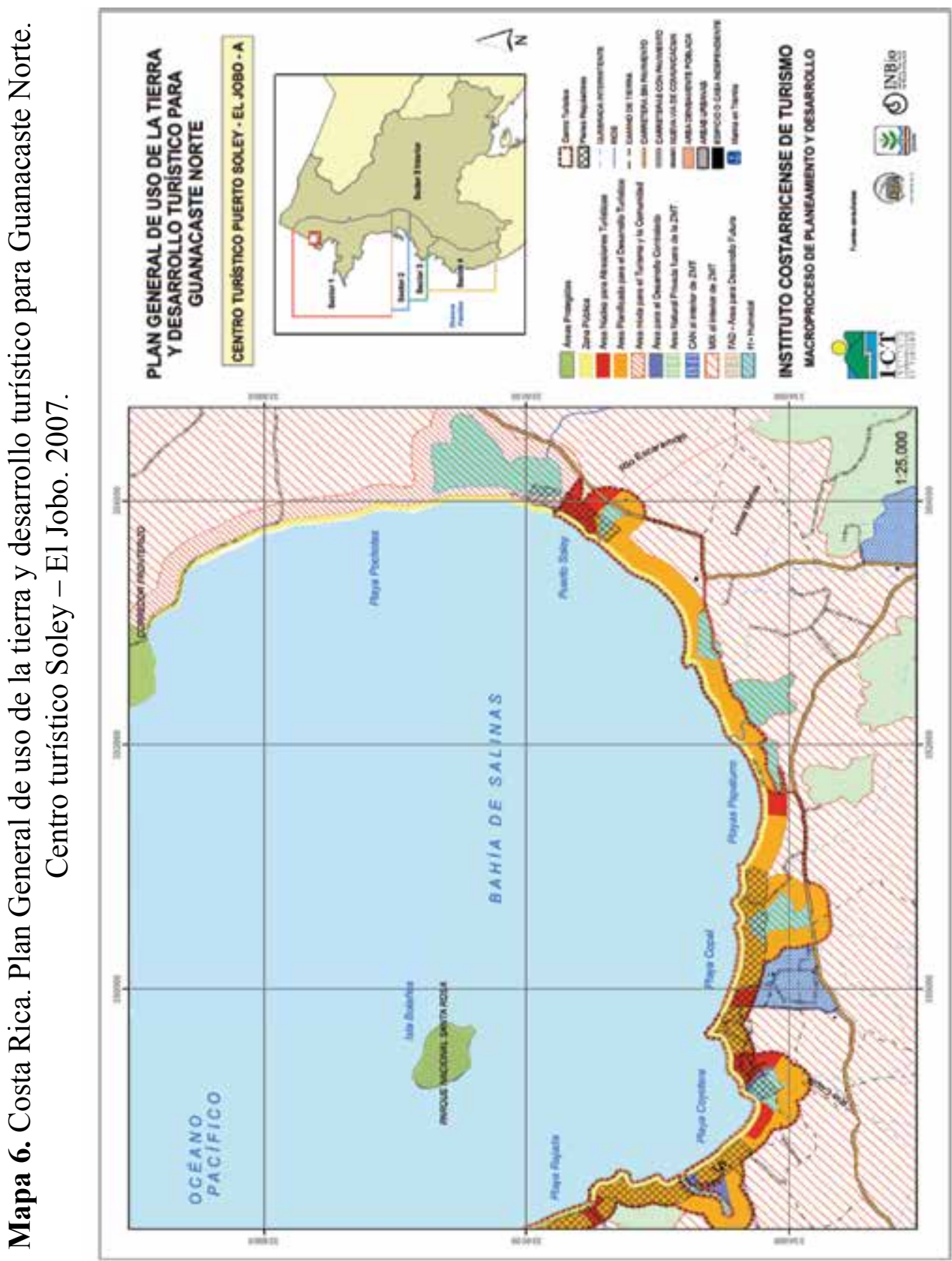


El proyecto consta de senderos dentro de la finca, en los cuales se ofrecen tours guiados; éstos se realizan caminando o a caballo, además de implementar medidas ambientales y utilización de sistemas de eficiencia energética. Los propietarios realizan esfuerzos por integrarse a la comunidad y contribuir con proyectos de desarrollo local. Una consciencia ambiental altamente desarrollada es la base fundamental del proyecto que iniciaron hace dos décadas, aunque han atravesado momentos difíciles por falta de visitación; sin embargo, manifiestan que mantienen una demanda constante durante todo el año.

\subsection{Proyecto Tour Científico - Cuajiniquil}

En el poblado de Cuajiniquil - Guanacaste, reside un poblador quien trabajó como guadaparque en el área marina protegida del Parque Nacional Santa Rosa, entre 1995 y 2000, actividad de la cual renunció para iniciar su propio emprendimiento; se lleva consigo toda su experiencia y sensibilidad ambiental. Opina que la cercanía al parque ha favorecido que el área no tenga un desarrollo fuerte; además de que la disponibilidad de agua limita la expansión de la economía turística. Su labor consiste en guiar grupos de turismo científico a realizar actividades acordes con la sostenibilidad ambiental, como snorking, buceo científico y viajes de observación. Trabaja con universidades que movilizan grupos de estudiantes con intereses científicos particulares, relacionados con el área marina.

En el momento de la entrevista atendía un grupo de diez estudiantes de la Universidad de California de un curso de Biología Tropical, quienes realizaban proyectos en el área marina: observación de corales, peces, garobos, gecos, del área protegida y de las áreas que se queman. En su bote, los traslada a los lugares recomendados, los acompaña en el recorrido y nutre la experiencia con el conocimiento de toda su vida. Este proyecto es liderado por un poblador que nació en Cuajiniquil, además del trabajo con muchos científicos sobre todo conocimiento de Biología; conoce a la perfección el mar, sus costas, sitios adecuados para la experiencia científica, ha tomado cursos dentro y fuera del país. En temporada alta, recibe de seis a ocho grupos al mes, de veinte personas cada uno; siendo la época de mayor afluencia de turismo científico es entre mayo y noviembre. A partir de diciembre, el agua está más fría y el viento fuerte, por lo que la visitación 
disminuye; no obstante, mantiene un número aceptable de visitantes; en promedio 600 personas al año.

Estos grupos se quedan en promedio tres meses, hospedados en casas de los vecinos, que ya tienen experiencia en hospedar este tipo de visitantes. Cuenta con una red de contactos comunales para suplir los servicios: la persona a quien le compran los maricos, el hotel, la señora que hace tortillas, un bote más que alquila; indirectamente se benefician de la actividad más de seis personas. Es contactado por medio de su página electrónica, correo electrónico o teléfono.

Mantiene una relación constante con el Parque Nacional Santa Rosa, que le envían personas que desean realizar este tipo de turismo científico; considera que el parque cree que ellos lo pueden hacer bien. Él entrevistado piensa que el turismo puede consolidarse siempre y cuando la gente sea responsable en sentido de la conservación, con los grupos de personas, los profesores, integrarse al grupo, química con la gente, disciplina. La pesca es menos productiva, da más a la gente la que se compromete con la actividad turística.

\subsection{Proyecto de Granos Básicos - La Virgen-Santa Cecilia}

Este proyecto fue fundado en el año 2005, atendido por una asociación de catorce mujeres y un hombre. Producen y comercializan granos básicos: frijoles, arroz y maíz, todo mediante tecnología orgánica, además de derivados maíz: pinol, pinolillo, pozol y pujagua. Desde hace cuatro años, iniciaron con el proyecto de turismo rural, realizan cabalgatas, caminatas por los senderos de la finca, llevan a los turistas a miradores con vista al Lago de Nicaragua. Demostraciones de las máquinas con las cuales procesan arroz y maíz, así como demostración de ordeño; adicionalmente, ofrecen alimentación. En un futuro cercano, están pensando construir cabinas para hospedar visitantes, ya cuentan con terreno disponible.

\subsection{Proyecto de Vainilla - Argendora - Santa Cecilia}

El proyecto de la Vainilla es atendido por un grupo de mujeres; consta de siete parcelas, de siete a ocho hectáreas cada una, tienen ocho años de producir vainilla. Al ser la vainilla una orquídea, constituye el nexo entre la parte forestal y los sistemas agroforestales, el productor obtiene cultivo de vainilla que se comercializa a un corto plazo y a largo plazo se obtiene la madera. 
La producción de este producto disminuye la presión sobre el bosque, a través de comercialización de la orquídea, la cual es económicamente rentable. Con asesoría de Instituto de Investigación y Servicios Forestales (INISEFOR) de la Universidad Nacional, este grupo de mujeres ha llevado adelante este proyecto. Además, de la venta de la vainilla, reciben turistas quienes visitan las plantaciones de vainilla mediante recorridos guiados.

\subsection{Tierra Madre Eco Lodge Hotel}

Este proyecto es iniciativa de una pareja de Belgas, quienes deciden establecerse en Costa Rica. Ubicado en un área con un excelente paisaje, una vista impresionante hacia el Lago de Nicaragua., que muestra la recuperación de lo que fueran fincas ganaderas ubicadas en las faldas de las montañas. En 2010, compraron una finca de 69 hectáreas, ahora en proceso de regeneración.

El hotel, ubicado en los Andes de La Garita en La Cruz de Guanacaste, consta de cinco cabinas para doce personas, la propuesta es un turismo de pequeña escala. Todo lo que consumen en el hotel es producido internamente, un huerto orgánico genera lo suficiente para preparar las comidas que se sirve a los visitantes. Los materiales de la construcción son fabricados con el mismo producto disponible en el suelo, y el aprovechamiento del paisaje y recursos del bosque. El sistema de alumbrado y generación eléctrica se realiza con paneles solares; los servicios sanitarios funcionan en seco, las duchas no generan aguas jabonosas que afecten el ambiente. Será un reto atraer turistas a un lugar de tan difícil acceso, el visitante que llegue hasta allí, realmente tiene una motivación especial. Los tours incluyen paseos y caminatas a caballo por la finca y senderos, visita a Cárdenas de Nicaragua y al Lago de Nicaragua.

\subsection{Otras actividades relacionadas}

Otras actividades, como el Festival de las Tortugas sugieren que hay intentos por acercar la comunidad al turismo y la conservación. Este festival se viene realizando desde el año 2009 y denota un turismo que pretende considerar las condiciones locales de los pobladores. A este festival los pobladores llevan sus artesanías, elaboradas con materiales locales, se dan charlas e información sobre la importancia de las tortugas y la necesidad de preservar esta especie. Constituye un espacio que empieza a 
ser reconocido por lugareños y foráneos, quienes disfrutan de conciertos, música, deporte y demostraciones con artistas locales. En 2014, se llevó a cabo el 22 y 23 de noviembre.

\subsection{Alternativas futuras: formación geológica geoturismo Santa Elena}

El Parque Nacional Santa Rosa, está propuesto como un geoparque, el cual parte de un concepto holístico de protección, educación y desarrollo sostenible, basado en sitios geológicos de particular importancia, rareza o estética ("geositios"). Un geoparque alcanza sus metas a través de tres grandes ejes: geoconservación, educación y geoturismo.

Mantesso-Neto, V.1; Mansur, 2; López, R.3; Schilling, M.4; Ramos, V. A. (ND). El primer geoparque del país estará basado en el actual Parque Nacional Santa Rosa, con 370 km 2 terrestres y 780 km 2 marinos, en el extremo NW del país, ya con estructura operacional. Posee elementos patrimoniales geológicos, biológicos e históricos.

\section{Conclusiones}

Los rasgos singulares del paisaje natural de Área de Conservación Guanacaste están conformados por una extensa plataforma marina y las zonas de costas adyacentes, así como una serranía alrededor del mar que se consideran las tierras más antiguas de Costa Rica. La prevalencia del bosque tropical seco, con sus ecosistemas asociados, el paisaje de sabana, la existencia de áreas naturales protegidas que albergan una variedad de recursos tanto naturales como culturales constituyen recursos del territorio que convierte este espacio en un sitio de gran belleza y potencial turístico.

El ACG declarada Patrimonio Mundial de la Humanidad por la UNESCO en 1999, es un sitio de investigación por parte de universidades nacionales y extranjeras, se considera que alberga más del $65 \%$ de la biodiversidad nacional. El área envuelve una variedad de atractivos turísticos desde la Casona de Santa Rosa, la Hacienda Murciélago y todos los recursos naturales y culturales contenidos en ellas; así como el llamativo atractivo de las playas pertenecientes al cantón de La Cruz, Punta Santa Elena, Puerto Soley, Junquillal y el Jobo.

El Parque Nacional Santa Rosa y el Parque Nacional Rincón de la Vieja, son los que reciben mayor visitación en el Área de Conservación 
Guanacaste; en el primero, destaca la visitación nacional, mientras que, la población extranjera visita el Parque Nacional Rincón de la Vieja. El área de estudio está siendo impactada por la actividad turística, modificando usos del suelo; el turismo espontáneo y no planificado, va a generar efectos no deseados para el ambiente y para las poblaciones locales, que por su potencial de recursos naturales y culturales, se convierten en objetos de consumo turístico. Una dinámica turística incipiente pero de crecimiento rápido caracteriza los alrededores del PNSR, especialmente en el área costera en los cuales ha incrementado su oferta hotelera, tal es el caso del sector entre el poblado Puerto Soley y la Rajada.

El turismo de sol y playa ha moldeado al igual que en otras áreas, la actividad turística; sin embargo, se observan algunas iniciativas distribuidas en el cantón, que aprovechan otros recursos naturales y culturales. Estas iniciativas de turismo sostenible han logrado articular elementos que podrían potenciar de mejor manera el desarrollo rural en el cantón, como el turismo a pequeña escala, utilización de materiales locales, producción agrícola orgánica, regeneración de espacios degradados, recuperación de áreas de bosque y ecosistemas asociados (flora - fauna), aprovechamiento paisaje y recursos del bosque, empleo mano obra familiar y local, generación de ingresos complementarios, encadenamientos productivos, recuperación cultural (tradiciones y costumbres) y fomento a sensibilización ambiental nuevas generaciones. Estas iniciativas requieren el incentivo y apoyo para ofrecer un servicio acorde a los requerimientos de los visitantes y ser articuladas con la oferta turística con que cuenta el cantón.

Los programas que el Área de Conservación Guanacaste ha establecido en las áreas aledañas a las áreas protegidas, como el Programa de Investigación, el Programa de Educación Ambiental y el Programa de Educación Biológica, evidencian un fortalecimiento en su relación con la comunidad. Estos programas iniciaron en los años noventa, considerando la participación de los últimos tres años de primaria y secundaria, hasta tercer año, siendo una vía para sensibilizar a la población local. Temas comunes como los incendios forestales han acercado a la comunidad y las áreas de conservación para evitar los impactos que los mismos conllevan a los recursos del área.

Siendo que el cantón de La Cruz, posee cerca del cincuenta por ciento de su área bajo alguna categoría de conservación, y siendo evidente de 
que las comunidades pueden articular actividades turísticas al gran potencial que posee el área, especialmente por su recurso natural principal el Parque Nacional Santa Rosa y las numerosas playas que lo rodean, se requieren grandes esfuerzos para que las comunidades se beneficien de poseer estos recursos. La organización es fundamental para articular esfuerzos y ofrecer una oferta turística coherente. Iniciativas que se visualizan a través de la Cámara de Turismo de La Cruz, de reciente fundación con el apoyo de las instituciones y organizaciones del cantón, entre ellas el Área de Conservación Guanacaste.

\section{Agradecimientos}

A Consuelo Alfaro Chavarría y Karla Mora Aparicio por su colaboración en la elaboración cartográfica.

\section{Referencias}

Amit, R., Alfaro, L. y Carrillo, E. (2007). Área De Conservación Guanacaste y Conservación del Jaguar. Revista Ambientico 169.

Área de Conservación Guanacaste. (2011). Compendio de Actividades de Educación Ambiental para Escolares de II Ciclo. Guanacaste, Costa Rica.

Blanco, M. (2007). Análisis del potencial de turismo rural en los cantones de Upala, Los Chiles, Guatuso y La Cruz. IICA- PRODAR. San José, Costa Rica.

Centeno, J., González, H. y López, N. (2012). Percepción de las comunidades sobre el ambiente y la relación con los parques nacionales cercanos. En: Comunidades y Áreas Silvestres Protegidas: identidad, convivencia y conservación ambiental/ Universidad Nacional (Costa Rica). Facultad de Ciencias Sociales. Instituto de Estudios Sociales en Población. II Edición (febrero 2012)- . Heredia.

Diegues, A.C. (2000). El mito de la naturaleza intocada. Quito, Ecuador; Abya Ayala.

Eagles, P., McCool, S. y Haynes, Ch. (2002). Turismo sostenible en áreas protegidas Directrices de planificación y gestión. Programa de las Naciones Unidas para el Medio Ambiente, la Organización Mundial del Turismo y la UICN - Unión Mundial para la Naturaleza 
Organización Mundial del Turismo Programa de las Naciones Unidas para el Medio Ambiente UICN-Unión Mundial para la Naturaleza.

Furst, E., Moreno, M., García, D., y Zamora, E. (2004). Desarrollo y conservación en interacción: ¿Cómo y cuánto se beneficia la comunidad de las áreas protegidas en Costa Rica? Costa Rica: CIMPE, UNA.

Instituto Costarricense de Turismo. (2007). Unidad de planeamiento Guanacaste Norte. Plan de Uso del Suelo y Desarrollo Turístico Macroproceso de Planeamiento y Desarrollo 2007. Costa Rica.

Instituto Costarricense de Turismo. (2010). Plan Nacional de Turismo Sostenible de Costa Rica, 2010 - 2016. San José, Costa Rica.

Instituto Costarricense de Turismo. (2013). Anuario Estadístico de Turismo 2013. Subproceso de Administración de la Información. San José, Costa Rica.

Blanco, M. (2007). Dinámicas territoriales en la Zona Norte de Costa Rica ( $2^{\mathrm{a}}$ ed.). Grupo Técnico de Apoyo IICA, PDR, CR. -- San José, C.R. Instituto Costarricense de Turismo (ICT). (2013). Anuario Estadístico de Turismo 2013. San José, Costa Rica.

Instituto Costarricense de Turismo (ICT). (2012). Anuario Estadístico de Turismo 2012. San José, Costa Rica.

INEC. (2011)Estado de la Nación, Indicadores cantonales Censos Nacionales de Población y Vivienda 2000 y 2011.

Instituto de Tierras y Colonización. (1979). Estudio socio-económico del grupo campesinos de Cuajiniquil Guanacaste. Departamento de selección y capacitación de beneficiarios. Costa Rica.

Nel, M. y Andreu, L. (2008). Organización y características del turismo rural comunitario en Costa Rica. Anales de Geografia, 28 (2), 167-188.

Maurín, M. (2008). Las áreas protegidas: un enfoque geográfico. Ería, 76, 165-195. Departamento de Geografía. Universidad de Oviedo.

Méndez, G. (2005). Estrategia marina del Área de Conservación Guanacaste. En Revista semestral de la Escuela de Ciencias Ambientales de la Universidad Nacional, 30. Heredia.

Panadero, M., Navarrete, G. y Jover, F. (2002). Turismo en espacios naturales: oportunidades en el corredor biológico mesoamericano. Cuadernos de Turismo, 10,69-83. 
Pauchard, A. (2000). La experiencia de Costa Rica en áreas protegidas. Revista ambiente y Desarrollo, XVI (3), 51-60.

Programa Estado de la Nación. (2008). Decimocuarto Informe Estado de la Nación en Desarrollo Humano Sostenible. San José, Programa Estado de la Nación.

TT Argos. (2008). Dinámica territorial del desarrollo turístico costero: Unidad Turística Guanacaste Norte. Este documento es parte del estudio "El Impacto del Desarrollo Asociado al Turismo en la Costa del Pacífico de Costa Rica". San José, Costa Rica.

Sánchez-Crispín A. y Propin, E. (2010). "Tipología de los núcleos turísticos primarios de América Central". Cuadernos de Turismo, 25, 165 184. Universidad de Murcia. Murcia, España. ISSN: 1139-7861.

Sequeira, W. (1985). La hacienda ganadera en Guanacaste, aspectos económicos y sociales 1850 - 1900. EUNED. San José.

Rodríguez, G. y Martínez, J. (2014). Informe de visitación 2013 Área de Conservación Guanacaste, Programa de Ecoturismo. Guanacaste, Costa Rica.

Vargas, G. (1982-1983). Origen y flora de las sabanas de la provincia de Guanacaste (Costa Rica): un análisis en la fitogeografía histórica. Revista Geográfica de América Central 17-18. pp.5 71-67.

Vargas, G. (2011). Estudio cartográfico de los cambios de la vegetación de sabana en el Parque Nacional Santa Rosa, Guanacaste, costa rica, 1985 - 2009. Revista Geográfica de América Central, 47, 71-96. Heredia.

Vargas, G. (2009). Turismo y Espacios Naturales Protegidos en Costa Rica: Enfrentamiento O Concertación. Revista Ciencias Sociales, 123-124: 49-78.

\section{Direcciones electrónicas}

ICT, (2014). http://www.visitcostarica.com/ict/paginas/es_parques_gua. asp

ACG, (2014). http://www.acguanacaste.ac.cr/biodesarrollo/programa-sectores/ sector-marino,

SINAC, (2012). http://www.sinac.go.cr/acg_santarosa_turistica.php

SINAC, (2012). http://www.sinac.go.cr/acg_santarosa_general.php 
SINAC, (2012). http://www.acguanacaste.ac.cr/biodesarrollo/ programa-de-ecoturismo)

SINAC, (2012). http://www.nacion.com/vivir/ciencia/Santa-Rosa-crearasendero-universal_0_1425857429.html

\section{Entrevistas}

Guadalupe Rodríguez (2014). Funcionaria del Parque Nacional Santa Rosa. (21 de agosto, 2014).Guanacaste, Costa Rica.

Neftali Mairena Corea (2014). Presidente de la Cámara de Comercio y Turismo de La Cruz - Guanacaste. (22 de agosto, 2014). Guanacaste, Costa Rica.

Mainor Lara (2014). Promotor de Tours Científico, Cuajiniquil. (20 Noviembre 2014). Guanacaste, Costa Rica.

Jorge Manuel Alan Fonseca (2014). Hotel Santa Elena Lodge (21 de agosto, 2014). Guanacaste, Costa Rica.

Claudio Belletti (2014). Cabinas Manglar (21 de agosto, 2014). Guanacaste, Costa Rica.

Patty Toledo. (2014). Hotel La Mirada. (22 de agosto, 2014). La Cruz, Guanacaste, Costa Rica.

Alexandra Gonzaga (2014). Funcionaria de Municipalidad de La Cruz (22 de agosto, 2014). Guanacaste, Costa Rica.

Gaby Somarribas Jones. Jefe Regional, Dirección Instituto de Desarrollo Rural (INDER). Liberia, 07 de mayo 2014. 